\title{
Buckling and Failure of Compression-loaded Composite Cylindrical Shells with Reinforced Cutouts
}

\author{
Mark W. Hilburger ${ }^{*}$ and Michael P. Nemeth ${ }^{\dagger}$ \\ NASA Langley Research Center, Hampton Virginia 23681-2199
}

\begin{abstract}
Results from a numerical and experimental study that illustrate the effects of selected cutout reinforcement configurations on the buckling and failure response of compressionloaded composite cylindrical shells with a cutout are presented. The effects of reinforcement size, thickness, and orthotropy on the overall response of compression-loaded shells are described. In general, reinforcement around a cutout in a compression-loaded shell can retard or eliminate the local buckling response and material failure near the cutout and increase the buckling load of the shell. However, some results show that certain reinforcement configurations can cause a significant increase in the local interlaminar failures that can accumulate near the free edges of a cutout during a local buckling event.
\end{abstract}

\section{Introduction}

Thin-walled shell structures are a fundamental component found in aircraft, spacecraft, and launch vehicles. In many applications, these structural components contain cutouts or openings that serve as doors, windows, or access ports, or are used to reduce weight. Often, some type of reinforcement is used around a cutout to eliminate local deformations and stress concentrations that can cause local buckling or premature material failures. Thus, it is important to understand how a cutout affects the baseline performance of a shell structure without a cutout, how loads are redistributed by cutout reinforcement, and how cutout reinforcement can be tailored to enhance performance and reduce weight. In addition, it is important to understand performance enhancements that can be obtained by using lightweight fiber-reinforced composite materials. Furthermore, these structures usually experience compression loads during vehicle operation and, as a result, their buckling response and failure characteristics must be understood and accurately predicted in order to develop efficient, safe designs.

Many numerical and experimental studies of the buckling behavior of cylindrical shells have been conducted since the early 1900 s. It took nearly 100 years to reach the point where robust, high-fidelity analysis tools and measurement technologies were available that could used to conduct test-analysis correlations that include the effects of initial geometric, material, and manufacturing imperfections and the effects of load introduction and support conditions. Two noteworthy studies conducted at the NASA Langley Research Center that document these advanced capabilities are given in Refs. 1 and 2. It is worth pointing out that these two studies show that differences as small as $5 \%$ between corresponding analytical and experimental results can be obtained for buckling and postbuckling of compression-loaded, laminated-composite, circular cylindrical shells. This small difference is on the same order as the error that inherently exists in the use of nominal material properties. Thus, technology and physical insight now exists that can be used to develop greatly improved buckling design criteria, such as that presented in Ref. 3. An important part of such an effort would, of course, need to include the effects of cutouts on the buckling performance.

In contrast to the body of work that exists for complete cylindrical shells and curved panels, studies that address the effects of a cutout on the buckling performance of cylindrical shells didn't appear until 1968. ${ }^{4}$ Since 1968, only about 20 studies have appeared that address the effects of unreinforced cutouts and that focus on the buckling behavior of compression-loaded isotropic and laminated-composite circular cylindrical shells and curved panels. ${ }^{5-25}$ Some of the general lessons learned from these studies are as follows. The presence of a cutout in an isotropic circular cylindrical shell can cause a localized response to occur near the cutout when the shell is loaded. This localized response typically consists of large out-of-plane deformations, large-magnitude stress concentrations, and rapidly varying stress gradients near the cutout. In a compression-loaded circular cylindrical shell, the cutout may cause a local buckling response to occur in the shell, near the cutout, at applied loads lower than the general

\footnotetext{
* Aerospace Engineer, Mechanics of Structures and Materials Branch, Member, AIAA.

${ }^{\dagger}$ Senior Research Engineer, Mechanics of Structures and Materials Branch, Associate Fellow, AIAA.
} 
instability load of the corresponding shell without a cutout. For some cases, this localized buckling is followed by a stable postbuckling response near the cutout, which is indicated by the fact that additional load can be applied to the shell before it exhibits overall collapse. However, other cases have shown that a local response in the shell can occur that causes a disturbance with enough kinetic energy to cause overall collapse to occur immediately after the local buckling occurs. Starnes ${ }^{6,11}$ suggested that the buckling of compression-loaded isotropic shells with a cutout is governed by the nondimensional geometric parameter $\tilde{a}=a^{2} / R t$, where $a$ is the characteristic cutout dimension and $R$ and $t$ are the shell radius and thickness, respectively. In addition, Starnes identified approximate ranges of the $\tilde{a}$ parameter that corresponded to the various behavioral trends described above.

For shallow, isotropic curved panels with a central circular cutout and subjected to compression loads, it has been found that cutout size greatly affects the nonlinear behavior. For example, it has been shown that curved panels with relatively small cutouts exhibit a linear prebuckling state followed by an unstable global buckling response and those with somewhat larger cutouts exhibit a nonlinear prebuckling state followed by an unstable global buckling response. As the cutout size gets even larger, the panels exhibit a monotonically increasing load-end-shortening response. These results suggest that traditional linear bifurcation buckling analyses may misrepresent the physics of the response for a certain range of cutout sizes because of significant nonlinear behavior and should not be used for design.

Numerical and experimental studies of the response of compression-loaded, laminated-composite, circular cylindrical shells with unreinforced rectangular cutouts indicate similar response characteristics to those exhibited by the corresponding isotropic shells. In addition, results have shown that localized regions of biaxial membrane compression stresses form in the shell near the cutout and that these regions of biaxial stresses couple with radial deformations of the shell wall, causing an unstable local buckling response to occur near the cutout. Hilburger et al. ${ }^{19,20}$ has shown that the buckling of compression-loaded anisotropic shells with a cutout is governed by a stiffness-weighted nondimensional geometric parameter, similar to that proposed by Starnes, and a stiffnessweighted cutout aspect ratio. In addition, the initial local buckling and postbuckling response near the cutout are characterized by large-magnitude deformations and stresses that cause material failure. Furthermore, laminate orthotropy and initial shell imperfections have been shown to have a significant effect on the nonlinear response and buckling behavior of a laminated-composite, circular cylindrical shell with a cutout.

Results for shallow, laminated-composite, curved panels with a central circular cutout and subjected to compression loads indicate similar trends to those exhibited by the corresponding isotropic shells. However, whether the panel exhibits an unstable snap-through-type buckling response or a monotonically increasing load-endshortening response, depends significantly on the panel orthotropy and anisotropy. Furthermore, numerical and experimental studies have identified cases where panels exhibited large-magnitude radial prebuckling deformations and buckling loads that exceeded the classical linear bifurcation buckling load. This behavior is contrary to previously known behavioral characteristics of compression-loaded shallow curved panels. It was determined that these response characteristics are caused by circumferential edge restraint on the loaded boundaries of the panels and indicated a high degree of boundary condition sensitivity.

Very few studies of the response of compression-loaded circular cylindrical shells and curved panels with reinforced cutouts have been conducted, and the majority of results that do exist are limited to isotropic shells (e.g., Refs. 13, 26). However, a recent numerical study of the response of compression-loaded, laminated-composite shells with reinforced cutouts was presented by Hilburger and Starnes. ${ }^{27,28}$ This work predicts that reinforcement can be placed around a cutout in a compression-loaded shell that will affect the local deformations and stresses near the cutout such that the onset of local buckling near the cut is retarded or suppressed, compared to the corresponding shell without cutout reinforcement. For some reinforcement configurations, the local buckling response is followed by a stable, local postbuckling response near the cutout and additional load can be applied to the shell before it undergoes a global collapse. For other configurations, the analyses predict that the local buckling response causes a disturbance with enough kinetic energy to cause the global collapse immediately after local buckling occurs. For still other configurations, the results predict that the reinforcement suppresses local buckling near the cutout and causes overall buckling to initiate in the bending boundary-layer regions near the ends of the shell.

Review of the literature cited herein indicates that the response of a compression-loaded cylindrical shell with an unreinforced cutout is becoming better understood. In addition, studies have been conducted that address numerical simulation of progressive failure in compression-loaded, laminated-composite, curved panels with a central circular cutout. $^{29,} 30$ However, the effects of cutout reinforcement on the buckling and failure of compression-loaded composite cylindrical shells, is not well understood. Therefore, the objective of the present study is to present numerical and experimental results that will identify typical buckling and failure response characteristics and trends for a compression-loaded, thin-walled, quasi-isotropic, laminated-composite, circular cylindrical shell with a square cutout and several cutout reinforcement configurations. This shell configuration represents a generic example of a 
typical aerospace shell structure with a cutout subjected to a destabilizing load. To accomplish this objective, selected experimental and numerical results that illustrate the buckling response of compression-loaded shells with unreinforced cutouts are presented first. Then, similar numerical and experimental results that show the effects of several different reinforcement configurations on the response of these shell structures are presented. The various cutout reinforcement configurations considered were used to study the effects of reinforcement orthotropy, thickness, and size on the response of the shell. Results obtained from an advanced high-fidelity nonlinear analysis procedure that includes the effects of initial geometric imperfections, thickness variations, and nonuniform load introduction is used in the study and offers the opportunity to provide insight into the effects of various cutout reinforcement concepts on the buckling and failure response of compression-loaded shell structures. In addition, preliminary results from a progressive failure analysis of selected shells are presented and include intralaminar and interlaminar failure modes in the failure analysis. The results include load-shortening response curves, out-of-plane displacement response curves and displacement contours, and descriptions of the observed shell buckling and failure responses.

\section{Test Specimens, Imperfection Measurements, and Tests}

\section{A. Test Specimens}

Fifteen test specimens were fabricated and tested in this investigation and include three cylinders with an unreinforced square-shaped cutout, referred to herein as specimens $\mathrm{C} 1-\mathrm{C} 3$, and twelve cylinders with reinforced square-shaped cutouts, referred to herein as specimens C4-C15. The specimens were fabricated from 12-in-wide, 0.005 -in.-thick AS4/3502 unidirectional graphite-epoxy tape material. The nominal unidirectional lamina properties of a typical 0.005 -in-thick ply with a fiber volume fraction of 0.62 are as follows: longitudinal modulus $\mathrm{E}_{1}=18.5$ Msi, transverse modulus $\mathrm{E}_{2}=1.64 \mathrm{Msi}$, in-plane shear modulus $\mathrm{G}_{12}=0.87 \mathrm{Msi}$, and major Poisson's ratio $v_{12}=$ 0.30 . The material was laid up by hand on a 15.75-in-diameter mandrel and vacuum bagged and cured in an autoclave to form shells with different 8-ply shell-wall laminates. These laminates include an axially stiff $\left[\mp 45 / 0_{2}\right]_{\mathrm{s}}$ laminate, a quasi-isotropic $[\mp 45 / 0 / 90]_{\mathrm{S}}$ laminate, and a circumferentially stiff $\left[\mp 45 / 90_{2}\right]_{\mathrm{s}}$ laminate $\left(\mathrm{a} 0^{\circ}\right.$ lamina ply and a $90^{\circ}$ lamina correspond to plies with fibers aligned along the length of the cylinder and around its circumference, respectively). A 1.0 -in by 1.0 -in square cutout with 0.05 -in-radius reentrant corners was machined in each cylinder at the shells mid-length. Twelve quasi-isotropic specimens were manufactured to include reinforcement around the cutout (specimens C4-C15). The addition of the reinforcement in the shell was achieved by including additional square-shaped pieces of unidirectional graphite-epoxy tape at the mid-surface of the laminate, aligned concentrically with the position of the square cutout. After curing, the cutout was carefully machined in the center of the reinforced region of the specimen thus creating a cutout with an annular region of reinforcement around its perimeter. Six reinforcement stacking sequences were considered in the present study that include $0,0_{2}, 0_{4}, 90,90_{2}$, and $90_{4}$ lay-ups. Three reinforcement sizes were also considered that include 2.4-in by 2.4in square, 4.4-in by 4.4-in square, and 8.0-in by 8.0-in square reinforcements. A list of shell identification codes and the corresponding reinforcements are given in Table 1. It is important to note that because the specimens were laid up on a uniform-diameter cylindrical mandrel, the shell-wall mid-surface in the region of the reinforcement had a radial eccentricity with respect to the nominal shell-wall mid-surface. The specimens had a nominal length $L$ equal to $16.0 \mathrm{in}$., a nominal radius $R$ equal to $8.0 \mathrm{in}$, and a nominal shell-wall thickness $t_{\text {nom }}$ equal to $0.04 \mathrm{in}$. Both ends of the specimens were potted in an aluminum-filled epoxy resin to ensure that the ends of the specimen did not fail prematurely during the test. The potting material extended approximately $1.0 \mathrm{inch}$ along the length of the specimens at each end, resulting in a test section that is approximately 14.0 in long. The ends of the specimens were machined flat and parallel to a tolerance of $\pm 0.001 \mathrm{in}$. to facilitate uniform load introduction during the tests. A typical cylinder specimen with a centrally located square cutout is shown in Fig. 1.

\section{B. Imperfection Measurements}

Three-dimensional surveys of the inner and outer shell-wall surfaces of the specimens were made prior to testing to determine the initial geometric shell-wall imperfection shape and the shell-wall thickness distribution. Measurements were taken over a uniform grid with increments of 0.125 in. in the axial direction and 0.139 in. (approximately $1^{\circ}$ of arc) in the circumferential direction over the exposed surfaces of each specimen. The inner surface measurement was used to determine the initial shell-wall geometric imperfection shape and the difference between the outer and inner surface measurements was used to determine the shell-wall thickness distribution. A plot of a typical nondimensionalized initial shell-wall geometric imperfection is shown in Fig. 2. The measured 
shell-wall imperfection $w_{o}$ is nondimensionalized by the nominal shell-wall thickness $t_{\text {nom }}=0.04$ inches of the unreinforced region of the shell. These results indicate that the initial geometric imperfection is periodic in the circumferential direction and has slight variations in the axial direction. The amplitude of the normalized shell-wall geometric imperfections of the specimens range from -1.33 $t_{\text {nom }}$ to $2.0 t_{\text {nom }}$. A plot of a typical shell-wall thickness variation is shown in Fig. 3. The measured shell-wall thickness $t_{o}$ is nondimensionalized by the nominal shell-wall thickness $t_{\text {nom }}$. These results indicate that the shell-wall thickness in the unreinforced region of the shell typically varies within each specimen from 0.93 to 1.3 times $t_{\text {nom }}$. The square-shaped reinforced region in this shell is clearly visible in the plot and indicates a thickness that ranges from 1.45 to 1.6 times $t_{n o m}$ and is typical for a four-ply-thick reinforcement that is nominally 1.5 times $t_{n o m}$. Most of the thickness variation throughout the specimen is attributed to local variations in the resin content of the laminate and outer-surface texture that results from the laminate fabrication process. However, gaps between adjacent pieces of graphite-epoxy tape in some of the laminate plies are generated during the lay-up and curing process. Such a region is referred to as a ply-gap. These locally thin regions of the shell wall have, associated with them, a significant mid-surface eccentricity and a reduced stiffness. The observed ply-gaps in the specimens have widths as large as $0.1 \mathrm{in}$. Similarly, local thick regions, other than the reinforcement, are attributed to ply overlaps.

To help characterized nonuniform load introduction effects, measurements of the top and bottom loading surfaces of the specimens were made at one-degree increments around the circumference of the specimen to determine the variation in the shell-end or loading-surface geometry. A typical top and bottom shell-end imperfection are denoted by $\delta_{t o p}$ and $\delta_{b o t}$, respectively, and are shown in Fig. 4. The average maximum amplitude of this shell-end or loading-surface variation is approximately \pm 0.0005 in., and corresponds to less than $0.01 \%$ of the nominal specimen length.

\section{Test Apparatus and Instrumentation}

The specimens were instrumented with electrical-resistance strain gages. In particular, sixteen back-to-back pairs of uniaxial strain gages were positioned around the perimeter of the cutout edge to characterize the rapidly varying strain gradients that develop during loading. These gages were aligned tangent to the cutout edge at the four corners and at the mid-length of each of the four sides, as shown in Fig. 5. In addition, far-field strain gages were positioned at several locations around the specimen to characterize the prebuckling load introduction into the specimen and load redistribution after local and global buckling occurs.

Direct-current differential transducers (DCDTs) were used to measure displacements. In particular, several DCDTs were positioned in the interior of the specimen to measure radial displacements near the cutout, as shown in Fig. 5a. In addition, three non-collinear DCDTs were positioned at three corners of the upper loading platen and used to measure the end-shortening displacement and the loading platen rotations, as shown in Fig. 1. Typical measured upper loading platen rotations $r_{y}$ and $r_{z}$ for a compression-loaded cylinder with a cutout are shown in Fig. 6 , where $r_{y}$ and $r_{z}$ denote dextral rotations about the $y$ and $z$ axis, respectively. These results indicate that significant loading platen rotation occurs from the onset of loading up to a load level of approximately $P / P_{c r}=0.1$. These rotations are attributed to initial misalignments between the specimen and the loading platen. The loading platen reaches an equilibrium position at approximately $P / P_{c r}=0.1$, and the loading of the specimen, for the most part, continues with out appreciable additional rotations until buckling occurs.

A shadow moiré interferometery technique was used to observe the shell-wall prebuckling, buckling, and postbuckling radial deformation patterns. All data were recorded with a data acquisition system, and the moiré patterns were recorded photographically, on videotape, and with a high-speed digital video camera. The high-speed digital video camera recorded images at a rate of $2000 \mathrm{~Hz}$.

The specimens were loaded in compression with a 120-Kip hydraulic universal-testing machine by applying an end-shortening displacement to the shell ends (loading surfaces) of a specimen. To control the load introduction into the specimen, the upper loading platen was aligned with the loading surface of the specimen before the test by adjusting leveling bolts in the corners of the upper loading platen until strains measured by selected far-field strain gages on the specimens indicated a uniform axial strain distribution around the circumference of the shell. The specimens were loaded until global collapse and failure of the shells occurred.

\section{Finite-element Models and Analysis Methods}

\section{A. Finite-Element Models}

All the shells considered in this study were analyzed with the STAGS (Structural Analysis of General Shells) nonlinear shell analysis code. ${ }^{31}$ STAGS is a finite-element code designed for the static and dynamic analysis of general shells, and includes the effects of geometric and material nonuniformities and progressive interlaminar and 
intralaminar material failure. The cylinders were modeled using the standard 410 quadrilateral elements from the STAGS element library. This element is a flat facet-type element based on Kirchoff-Love thin shell theory and the nonlinear Lagrangian strain tensor. Geometrically imperfect shells were analyzed in the present investigation and the finite-element models used herein are based on similar high-fidelity cylinder models developed previously for predicting the elastic buckling response of geometrically perfect and imperfect compression-loaded cylinders. ${ }^{1,2}$ The geometrically imperfect models include the effects of the measured shell imperfections to more closely simulate the response of the specimens. The imperfection considered include, initial shell-wall geometric imperfections, shellwall thickness variations, thickness-adjusted lamina properties, and nonuniform load introduction effects. A more thorough explanation of model development and validation procedures for high-fidelity modeling of imperfect compression-loaded composite laminated shells with and without cutouts is presented in Refs. 1 and 2. In addition, selected models were modified to include the effects of progressive intralaminar and interlaminar material failures and preliminary results from these analyses are presented herein. The progressive failure methodology is described next.

\section{B. Progressive Failure Methodology}

Intralaminar material failures were predicted by using the $\operatorname{Hashin}^{32}$ failure criteria. The progressive failure theory and implementation are discussed in Ref. 29 and 30. Some relevant details are presented subsequently.

The intralaminar failure modes considered include matrix cracking, fiber-matrix shear failure, and fiber failure. To apply the failure criterion, the stress state is analyzed at each material point in the finite element model for a given solution step in the analysis. If the failure criteria is met (i.e., if the Hashin failure index exceeds a value of 1.0) then it is assumed that the material at point has failed and the material stiffnesses at that point are then degraded according to the Chang and Lessard degradation model. ${ }^{33}$ Material allowables used in the present study for AS4/3502 material are as follows: in-plane shear stress allowable $S_{12}=25.5 \mathrm{ksi}$, longitudinal tension and compression stress allowables $X_{t}=200.0 \mathrm{ksi}$ and $X_{c}=180.0 \mathrm{ksi}$, respectively, and transverse tension and compression stress allowables $Y_{t}=12.6 \mathrm{ksi}$ and $Y_{c}=24.6 \mathrm{ksi}$, respectively.

The initiation and progression of interlaminar, delamination failures are predicted by using a decohesion element that is positioned between composite laminae in potential delamination locations. A material-softening constitutive law developed by Goyal et al. ${ }^{30}$ is used in the formulation of the decohesion element. This constitutive law governs the initiation of a delamination and the subsequent delamination growth. The initiation of a delamination is specified to occur when the maximum interfacial strength between plies is exceeded and subsequent propagation of the delamination occurs when the fracture energy release rate is exceeded. The interfacial material failure properties used in the present study for AS4/3502 are as follows: the critical energy release rates $\mathrm{G}_{\mathrm{Ic}}=1.13 \mathrm{lb} / \mathrm{in}$, and $\mathrm{G}_{\mathrm{IIc}}=$ $\mathrm{G}_{\text {IIIc }}=3.3 \mathrm{lb} / \mathrm{in}$. The maximum interfacial strengths $\mathrm{T}_{1}{ }^{\mathrm{c}}=9.0 \mathrm{ksi}$, and $\mathrm{T}_{2}{ }^{\mathrm{c}}=\mathrm{T}_{3}{ }^{\mathrm{c}}=10.5 \mathrm{ksi}$. The decohesion element was implemented in the STAGS finite-element code as a user-defined element.

\section{IV.Results and Discussion}

Numerically predicted and experimentally measured results for fifteen compression-loaded composite cylindrical shells with unreinforced and reinforced cutouts are presented in this section. The predicted results were obtained from finite-element analyses of geometrically imperfect shells that include the effects of initial shell-wall geometric imperfections, shell-wall thickness variations, thickness-adjusted lamina properties, and nonuniform load introduction effects. First, results are presented for three cylinders with different laminate stacking sequences and with unreinforced cutouts to illustrate the effects of laminate orthotropy on the buckling and failure response of the shells and to provide a baseline for comparison with the corresponding shells with reinforced cutouts. Then, similar results are presented for selected quasi-isotropic shells with reinforced cutouts to illustrate the effects of reinforcement orthotropy, size and thickness on the buckling and failure response of the shells. Finally, overall response trends are identified and discussed. The results include load-shortening response curves, load versus outof-plane displacement response curves, load-strain response curves, and observed and predicted radial deformation patterns and material failures. The values of axial load $P$, presented herein, are normalized with respect to the linear bifurcation buckling load of a geometrically perfect, quasi-isotropic cylinder without a cutout, $P_{c r}{ }^{o}=42,590 \mathrm{lb}$. Radial displacements are normalized by the nominal shell-wall thickness $t_{\text {nom }}=0.04 \mathrm{in}$. and end-shortening displacements are normalized by the specimen length $L=16.0$ in., respectively.

\section{A. Shells with an Unreinforced Cutout}

Measured load-end-shortening response curves for the three cylinders with unreinforced cutouts, C1 ([$\left.\mp 45 / 0 / 90]_{\mathrm{s}}\right), \mathrm{C} 2\left(\left[\mp 45 / 0_{2}\right]_{\mathrm{s}}\right)$, and C3 $\left(\left[\mp 45 / 90_{2}\right]_{\mathrm{s}}\right)$, considered in this study, are shown in Fig. 7. Buckling loads are 
indicated by filled circles and global collapse loads are indicated by an $\mathbf{X}$. The cylinders exhibit a linear prebuckling load-shortening response up to buckling (note: the initial nonlinearity in the prebuckling response is attributed to the usual initial misalignment between the specimen and the loading platen). Cylinders $\mathrm{C} 1$ and $\mathrm{C} 2$ exhibit a local buckling response at normalized load levels of 0.48 and 0.39 , respectively. The buckling response is characterized by a localized, unstable dynamic buckling event in the cylinder and includes the formation of large-magnitude radial deformations and rapidly varying strains near the cutout. It has been shown by Hilburger et al. ${ }^{19,} 20$ that this local buckling response is caused by nonlinear coupling between the compressive membrane biaxial stresses and the radial deformations that occur near the cutout. A stable post-local-buckling response is exhibited by specimens $\mathrm{C} 1$ and $\mathrm{C} 2$ and additional load is carried by these shells until global collapse occurs at load levels of 0.52 and 0.41 , respectively. As loading continues in the post-local-buckling region of the response, these shells exhibit a slight reduction in the effective axial stiffness. This reduction in axial stiffness, manifested by a change in slope of the response curves, is caused by increasingly large out-of-plane deformations that develop in the shell and cause a redistribution of load away from the cutout, thereby reducing the effective load-carrying cross-section of the shell. The global collapse response is characterized by a significant reduction in axial load and the development of the general instability deformation pattern. Specimens $\mathrm{C} 1$ and $\mathrm{C} 2$ obtain stable post-collapse equilibrium at load levels of 0.32 and 0.23 , respectively and can sustain additional loading until complete failure of the cylinders occurs due to significant accumulation of material failures in the shell wall. In contrast, shell C3 exhibits an unstable local buckling response, at a load of 0.51 , that caused a catastrophic failure of the specimen and, as a result, there was no residual post-buckling strength for this specimen.

The results in Fig. 7 and results in Ref. 1 also indicate that the measured initial buckling load of specimens with a cutout are an average of $37.3 \%$ less than the measured buckling loads of the corresponding specimens without a cutout. However, there are no noticeable differences in the prebuckling stiffnesses of the specimens with the same laminate, regardless of whether there is a cutout or not. Moreover, the measured post-buckling loads for specimens $\mathrm{C} 1$ and $\mathrm{C} 2$ after global collapse are 2.1 and $1.4 \%$ greater than the corresponding buckling loads for the shells without cutouts and indicates that, in some cases, the cutout can have a relatively small effect on the post-buckling strength of these specimens.

Measured out-of-plane displacements for specimens C1, C2, and C3 are shown in Fig. 8 and selected observed local buckling and global collapse radial deformation patterns for specimens $\mathrm{C} 1$ and $\mathrm{C} 2$ are shown in Figs. 9 and 10, respectively. The displacement measurements were taken at the upper right corner of the cutout. Positive displacement values correspond to inward radial deformations of the shell wall. The results in Fig. 8 indicate that the specimens exhibit small radial pre-buckling deformations. During the local buckling response, cylinders $\mathrm{C} 1$ and $\mathrm{C} 2$ exhibit radial displacements at the corner of the cutout equal to approximately -1.0 and +1.5 times the nominal shell-wall thickness, respectively. After global collapse, the specimens exhibit displacements of approximately +3.0 and +2.0 times the shell-wall thickness. Specimen $\mathrm{C} 2$ exhibits inward deformations throughout the local buckling and global collapse response at this corner of the cutout. The local-buckling deformation response consists of large ellipse-like buckles on either side of the cutout and are aligned in a helical or skew direction (see Fig. 10a). After additional load is applied, the specimen collapses into a general instability buckling pattern in which the local buckles near the cutout increase in size and magnitude, and additional buckles develop around the circumference of the specimen (see Fig. 10b). In contrast, specimen $\mathrm{C} 1$ buckles into an asymmetric local buckling deformation pattern with an outward displacement of the upper right corner of the shell, but then exhibits a snap-through response upon global collapse, as indicated in Fig. 8. The asymmetric local buckling deformations are shown in Fig. 9a and the global collapse deformations are shown in Fig 9b. The apparent snap-through behavior in specimen $\mathrm{C} 1$ is associated with a significant increase in the size and magnitude of the local inward buckle located at the right side of the cutout. This response causes the appearance of a local snap-through response in the measured displacements near the upper right corner of the cutout. The asymmetry in the deformation response is attributed to initial geometric imperfections in the specimen. Post-buckling displacement data for shell C3 has been omitted because the DCDT lost contact with specimen as a result of the buckling and failure event.

Typical measured strain results for specimens C1, C2, and C3 are shown in Fig. 11. The figure includes data from three axially aligned back-to-back strain gage pairs located at the right edge of the cutout in specimens C1-C3. The solid and dashed lines denote measured strain data from gages located on the outer shell-wall surface and the inner shell-wall surface, respectively. In general, the results indicate that specimens $\mathrm{C} 1$ and $\mathrm{C} 2$ exhibit some local bending during the prebuckling response, as indicate by the divergence of the back-to-back strain gage curves, and have maximum strains that approach $0.6 \%$ strain. The strains near the cutout in specimens $\mathrm{C} 1$ and $\mathrm{C} 2$ increase significantly when local buckling and global collapse occur and can exceed $2.0 \%$ strain. Once local buckling occurs, these large-magnitude bending strains near the cutout activate an interlaminar shear failure mechanism in specimens $\mathrm{C} 1$ and $\mathrm{C} 2$, as shown in Fig. 12 for specimen $\mathrm{C} 1$. The local interlaminar shear failures that developed in 
specimens $\mathrm{C} 1$ and $\mathrm{C} 2$ typically propagate approximately $0.5 \mathrm{in}$. beyond the free edge of the cutout around the circumference of the shell. In contrast, specimen $\mathrm{C} 3$ exhibits significant bending from the onset of loading and these large-magnitude bending strains activate an interlaminar shear failure mechanism prior to buckling. The initial local failures that occur near the cutout in shell $\mathrm{C} 3$ propagated around the circumference of the specimen very rapidly and, as a result, this specimen had no post-buckling strength, as shown in Fig 13.

Predicted results were obtained for the three shell specimens with unreinforced cutouts and include load-endshortening response curves; pre-buckling, buckling, and post-buckling deformations; and selected results that illustrate the progressive interlaminar and intralaminar failure response of these shells. Some of these results have been presented in Refs. 27 and 28, and thus, only highlights are presented here along with new results from a progressive failure analysis. In particular, predicted normalized buckling loads for shells $\mathrm{C} 1, \mathrm{C} 2$, and $\mathrm{C} 3$ that include the effects of initial imperfections and loading nonuniformities are $0.51,0.40$, and 0.56 , respectively, and are approximately $6.0 \%, 2.5 \%$, and $9.8 \%$ greater than the corresponding measured results. A summary of these measured and predicted buckling loads is presented in Table 1. In addition, results from a previous study presented in Ref. 1 indicate that the initial geometric imperfections and thickness variations cause a $13.9 \%, 2.6 \%$, and $1.3 \%$ reduction in the buckling loads for shells $\mathrm{C} 1, \mathrm{C} 2$, and $\mathrm{C} 3$, respectively, with respect to the predicted linear bifurcation buckling loads for the corresponding geometrically perfect shells. The results suggest a relatively small degree of imperfection sensitivity for these shells. Similarly, nonuniform loading caused by shell-end imperfections and loading platen rotations caused a $12.2 \%, 31.2 \%$, and $1.3 \%$ reduction in the buckling loads of shells $\mathrm{C} 1, \mathrm{C} 2$, and $\mathrm{C} 3$, respectively. In particular, the significant reduction in the buckling load exhibited by shell $\mathrm{C} 2$ is attributed to a relatively large magnitude shell-end imperfection that causes nonuniform end loading. The magnitude of this shellend imperfection was approximately $60 \%$ of the magnitude of the end-shortening displacement of the shell at buckling. In addition, the predicted local buckling displacements and general instability displacements agree well with the observed displacements from the tests (see Figs. 9 and 10, for shells $\mathrm{C} 1$ and $\mathrm{C} 2$, respectively). For example, typical predicted initial local buckling deformations are shown for shell $\mathrm{C} 1$ in Fig. 14a and indicate an asymmetric buckling response in the shell near the cutout similar to that exhibited by specimen $\mathrm{C} 1$ shown in Fig 9. The asymmetry in the local response is attributed to an initial geometric imperfection in the shell wall near the cutout that appears to have a greater influence over the local deformations in shell than the cutout. Predicted intralaminar and interlaminar material failures incipient to global collapse for shell $\mathrm{C} 1$ are shown in Figs. 14b and $14 \mathrm{c}$, respectively. The results indicate some intralaminar failures in the upper and lower right corners of the cutout in the form of matrix tension failures and fiber compression failures. However, the analysis also predicts the initiation and propagation of significant interlaminar shear-type failures near the free-edge of the cutout (see Fig 14c). The location and the extent of the damage in the shell appears to agree well with the observed damage shown in Fig. 12. Similar failure predictions were obtained for shell C2 and C3. Predicted delamination type failures in shell $\mathrm{C} 2$ are less pronounced than those predicted for shell $\mathrm{C} 1$ and agree well with the observed failure response in the shell. Preliminary failure predictions obtained for shell C3 indicate an increased potential for the initiation of interlaminar failures at the edges of the cutout and the rapid propagation of these delaminations around the circumference of the shell, as observed in the test (see Fig. 13). This increased potential for interlaminar shear failures is due to relatively large-magnitude bending strains ( $>1 \%$ strain) and deformations near the cutout, as compared to the strains exhibited by shells $\mathrm{C} 1$ and $\mathrm{C} 2$. In addition, it is well established that delamination-type failures will initiate and propagate more easily in a structure where the lamina fibers are oriented parallel to the direction of propagation. However, convergence difficulties in the numerical solution associated with a rapid reduction in local shell wall stiffness during the quasi-static progressive failure analysis did not permit the analysis to predict the full extent of the catastrophic failure observed in the test. It may be possible to overcome these convergence difficulties by using a transient analysis capability in STAGS coupled with the progressive failure analysis capability, however, this analysis option is not currently available.

\section{B. Shells with a Reinforced Cutout}

The measured results for the compression loaded shells $\mathrm{C} 1, \mathrm{C} 2$, and $\mathrm{C} 3$ with unreinforced cutouts, presented in the previous section, and predicted results presented herein and in previous work ${ }^{1}$, identified several features of the behavior that are associated with the local buckling and failure response of the shells. In particular, the nonlinear interaction between the local radial deformations and destabilizing biaxial stresses near the cutout cause the local buckling response to occur. The magnitude of the deformations and strains near the cutout, as indicated by DCDT and back-to-back strain gage measurements and verified by analysis, are affected by laminate orthotropy. Furthermore, local interlaminar shear failures develop near the cutout in the post-local-buckling region of loading and the extent to which these failures occur is affected by the local deformations and laminate orthotropy. These fundamental behavioral characteristics suggest that it may be possible to retard or eliminate the onset of the local 
buckling and failure response near the cutout if a cutout reinforcement configuration can be identified that reduces the local deformations or the local stresses near the cutout.

Prior to conducting the test presented herein, a numerical parametric study was conducted to identify the effects of selected cutout reinforcement configurations on the response of similar compression-loaded shells with a cutout. ${ }^{27,28}$ The reinforcements investigated consisted of square-shaped, concentrically aligned lamina plies added to the shell-wall mid-surface. Three reinforcement sizes and three reinforcement thicknesses, including 1-ply-thick, 2-ply-thick, and 4-ply-thick reinforcements, were studied to identify the effects of reinforcement size and thickness on the deformation response and stress distribution in the shell. In addition, two reinforcement ply orientations of $0^{\circ}$ and $90^{\circ}$ were investigated to study the effects of reinforcement orthotropy on the response. Some of the general trends identified in the study that are relevant to the tests presented herein are as follows. The reinforcement can retard or suppress the onset of local buckling in the shell near the cutout. For some cases, the local buckling response near the cutout results in a stable post-local-buckling response near the cutout and additional load can be applied to shell before global collapse. For other cases, the local response near the cutout in the shell causes a disturbance with enough kinetic energy to cause the overall collapse of the shell immediately following the local instability. The results indicate, for the most part, that the buckling load of a shell with a $90^{\circ}{ }^{\circ}$ ply cutout reinforcement is greater than the buckling load of the corresponding shell with a $0^{\circ}$-ply cutout reinforcement.

Based on the results of the numerical study, described above, a similar set of twelve [ $\mp 45 / 0 / 90]_{\text {s }}$ quasi-isotropic shells with reinforced cutouts were fabricated and tested to verify the predicted response trends (see Table 1). Selected measured results from these twelve compression-loaded shells, C4-C15, with 1.0-in-square reinforced cutouts are presented in this section to identify the potential for using cutout reinforcements to enhance the buckling and failure response of the shells with cutouts. The results for these shells are compared to results for the corresponding shell $\mathrm{C} 1$ with an unreinforced cutout. First, experimentally measured results that illustrate the effects of cutout reinforcement thickness and orthotropy on the typical buckling and failure response characteristics for compression-loaded shells with a 4.4-in.-square cutout reinforcement are presented. Then, results summarizing the effects of cutout reinforcement size, thickness, and orthotropy on the buckling and failure of a shell with a reinforced cutout are presented. Selected predicted results that were obtained from finite-element analyses of imperfect shells are also presented to illustrate the effects of initial imperfections on the buckling response of the shells.

\section{4.4-in. Square Reinforcement}

Results for shells C4-C9 are presented in this section. The cutout reinforcements for shells C4 through C6 consist of 4.4-in square-shaped $0^{\circ}$ lamina plies and the cutout reinforcements for shells C7-C9 consist of 4.4-in square-shaped $90^{\circ}$ lamina plies. Measured load-shortening response curves for shells C1 (no reinforcement), and C4-C6 are presented in Fig. 15. The results show that the increasing the amount of reinforcement has a significant effect on the overall character of the shell response. In particular, the normalized buckling loads increase by as much as $56 \%$ as the thickness of the reinforcement increases. Specifically, the normalized buckling loads for shells $\mathrm{C} 4, \mathrm{C} 5$, and $\mathrm{C} 6$, with $0^{\circ}$-ply reinforcement are equal to $0.67,0.74$, and 0.75 , respectively. The normalized buckling load for the corresponding unreinforced shell $\mathrm{C} 1$ is 0.48 . In addition, the results indicate that the shells with the reinforcement do not exhibit stable post-local-buckling responses. For these shells, the local-buckling response causes a disturbance with enough kinetic energy to cause global collapse of the shell. After global collapse occurs, each shell has a stable post-collapse configuration, accompanied by a significant reduction in the axial load. The normalized post-collapse loads range from 0.26 and 0.27 for shells $\mathrm{C} 4$ and $\mathrm{C} 5$, respectively, to 0.34 and 0.35 for shells $\mathrm{C} 1$ and $\mathrm{C} 6$, respectively. In general, these response trends agree well with the corresponding numerically predicted results for geometrically perfect shells presented in Refs. 27 and 28 and the predicted buckling loads for imperfect shells presented in Table 1. In particular, the predicted buckling loads are $1.4 \%, 5.4 \%$, and $6.7 \%$ greater than the experimentally measured results for specimens C4- C6, respectively.

Measured radial displacements for shells $\mathrm{C} 1$ and $\mathrm{C} 4$ through $\mathrm{C} 6$ are presented in Fig. 16, and observed out-ofplane deformations patterns of the local buckling and collapse response of shells C4-C6 are shown in Figs. 17-19, respectively. The displacement measurements were taken at the upper right corner of the cutout. Positive displacement values correspond to inward deformations of the shell wall. The moiré fringe patterns shown in Figs. 17-19 were obtained by using a high-speed digital video camera with a frame rate of $2000 \mathrm{~Hz}$. The dashed lines in Figs. 17-19 outline the edges of the cutout reinforcement. The results in Figs. 16-19 indicate that the shells prebuckling and buckling deformation response near the cutout can change significantly with an increase in the reinforcement thickness. In particular, local buckling in shell $\mathrm{C} 4$ initiates near the cutout and is characterized by a rapid increase in local out-of-plane deformations, as indicated by the displacements incipient to and during the initial local buckling response, as shown in Fig. 16. At the onset of buckling, a local unstable response occurs in the shell 
and is characterized by the development of localized ellipse-shaped buckles near the cutout, as shown in Figs. 17a (time $=0.0$ seconds) and $17 \mathrm{~b}$ (time $=0.001$ seconds). This local buckling response in the shell triggers the global collapse of the shell, as indicated in Figs. $17 \mathrm{c}$ (time $=0.002$ seconds) and $17 \mathrm{~d}$ (time $=0.004$ seconds), and is accompanied by a significant increase in the local displacements near the cutout. The density of the fringes in the moiré patterns is indicative of the shell-wall bending gradients. The post-collapse displacements near the corner of cutout are approximately +2.4 times the nominal shell-wall thickness. In contrast, the buckling response for shells C5 and C6 is characterized by a single, small-magnitude, ellipse-shaped buckle that forms at the edge of the cutout reinforcement, as shown in Figs 18a (time $=0.0005$ seconds) and 19a (time $=0.0005$ seconds), respectively. The local buckles are marked with an $\mathbf{X}$ symbol in the figures. At the onset of buckling, a local unstable response occurs in shell C5 and C6 that is characterized by a significant increase in the size and magnitude of the ellipse-shaped buckle, as shown in Figs $18 \mathrm{~b}$ (time $=0.001$ seconds) and $19 \mathrm{~b}$ (time $=0.001$ seconds), respectively. The lack of symmetry in the response is attributed to the effects of initial geometric imperfections in the shell wall. As the buckling process continues, the local buckles in the deformation pattern rapidly increase in number and become distributed around the circumference of the shell and are associated with the overall collapse of the shell, as shown in Figs 18c (time $=0.002$ seconds) and $18 \mathrm{~d}$ (time $=0.004$ seconds) for shell C5, and Figs. $19 \mathrm{c}$ (time $=0.002$ seconds) and $19 \mathrm{~d}$ (time $=0.004$ seconds) for shell C6. The post-collapse displacements near the corner of cutout in shell C5 are approximately +2.4 times the nominal shell-wall thickness and the overall character of the deformation pattern is similar to that exhibited by shell C4 shown in Fig. 17d. However, the post-collapse displacements and bending gradients near the cutout in shell C6 (see Figs. 19c and 19d) are reduced significantly, compared to shells C4 and C5 shown in Figs. 17d and 18d, respectively. Specifically, the moiré fringe patterns in Figs 19c and 19d indicate a marked reduction in local bending near the cutout as compared to the corresponding fringe patterns observed for shells C5 and C6.

Typical measured strain results for specimens C1, C4- C6 are shown in Fig. 20. The figure includes data from four back-to-back strain gage pairs at the upper right corner of the cutout, aligned tangent to the edge. The solid and dashed lines denote measured strain data from gages located on the outer shell-wall surface and on the inner shellwall surface, respectively. The results show that the local pre-buckling and post-buckling bending strains near the cutout, indicated by the divergence of the curves for the back-to-back strains, are significantly reduced with an increase in the thickness of the reinforcement, as expected. In particular, local pre-buckling strains in shell C1 (unreinforced cutout) approach 5000 microstrain and rapidly increase to over $\pm 15,000$ microstrain (1.5\% strain) during global collapse. In contrast, shell C6 exhibits relatively low-magnitude prebuckling strains of -1500 and 2500 microstrain on the inner and outer surface of the shell, respectively. At buckling, the bending strains in the corner of the cutout in shell C6 increase, but not to the extent exhibited by the other three shells. For the most part, the largest-magnitude strains develop in the corners of the shell and correspond to the locations where the majority of the material failures were observed. Observed failures for the unreinforced shell $\mathrm{C} 1$ are shown in Fig 12 and indicate significant delamination along the entire free edge of the cutout. The damage in shells C4 and C5 is generally much less severe, as indicated in Fig. $21 \mathrm{a}$, and is characterized by delaminations in the upper left and lower right corners of the cutout. In contrast, no damage was evident near the cutout in shell C6 during the test, rather, interlaminar and intralaminar material failures developed away from the cutout in regions of the shell that exhibited large-magnitude bending gradients associated with the nodal lines between adjacent buckles in the general instability deformation response, as shown in Fig. $21 \mathrm{~b}$.

In general, the corresponding experimental results for shells C7- C9 with $90^{\circ}$ ply reinforcements exhibit very similar response trends as those for shells $\mathrm{C} 4-\mathrm{C} 6$ with $0^{\circ}$ ply reinforcements, presented previously. However, more extensive delamination failures develop near the cutouts in shells C7 and C8, shells with 1-ply-thick and 2-ply-thick $90^{\circ}$ ply reinforcements, respectively, than the failures exhibited by the corresponding shells $\mathrm{C} 4$ and $\mathrm{C} 5$ with $0^{\circ}$ ply reinforcements. This failure trend is similar to that exhibited by the unreinforced shells, in which shell $\mathrm{C} 3$ $\left(\left[\mp 45 / 90_{2}\right]_{\mathrm{s}}\right)$ developed catastrophic delamination failures near the cutout, compared to shells $\mathrm{C} 1$ and $\mathrm{C} 2$ which exhibited relatively small amounts of failure near the cutout in the post bucking region of the response.

\section{Response Trends}

Buckling and failure trends for the fifteen shells tested in this study are presented in this section. In addition, selected predicted results are presented to illustrate the effects of initial imperfections on the buckling response of shells with reinforced cutouts and to verify some the behavioral characteristics observed in the tests.

Measured and predicted buckling loads for all fifteen specimens considered in the present study have been summarized in Table 1. These results indicate that, for the most part, the buckling load of the quasi-isotropic shell increases as the reinforcement size and thickness increases. In addition, the results indicate that the buckling load of the shell with the $90^{\circ}$-ply reinforcement configuration is slightly greater (on average $4.5 \%$ greater) than the buckling 
load of the corresponding shell with the $0^{\circ}$-ply reinforcement. These buckling-load trends agree well with the predicted trends presented in Refs. 27 and 28 for similar geometrically perfect shells with reinforced cutouts. However, the experimentally measured results and predicted results for imperfect shells indicate an average increase in the shell buckling load of only $2.9 \%$ when the reinforcement thickness is increased from a 2-ply-thick reinforcement configuration to a 4-ply-thick reinforcement configuration, for the same reinforcement size and ply orientation. In contrast, the predicted results for geometrically perfect shells presented in Refs. 27 and 28 indicate an average increase in the shell-buckling load of approximately of $18.1 \%$. These results suggests that, as the reinforcement thickness increases, the shell may be becoming more imperfection sensitive, and this imperfection sensitivity is negating any additional improvements in the buckling load of the shell. Similarly, the specimen reinforcement configurations tested in this study include a slight outward shell-wall mid-surface eccentricity that results from the manufacturing process. This eccentricity detail was included in the analysis models of the imperfect shells presented herein, but was not included in the geometrically perfect shell analysis models reported in Refs 27 and 28. Thus, it is also likely that local bending is occurring in the specimens near the edges of the reinforcement region due to the discontinuity in the mid-surface geometry at this location, and that this bending response is triggering a local buckling response in the shell at lower applied load levels.

Shells with unreinforced cutouts (C1-C3) and shells with relatively thin reinforcements (C4, C7, and C8) exhibit a local buckling response near the cutout (see initial buckling deformations in Fig 17a for shell C4). Shells with thicker reinforcement, however, exhibit initial buckling just outside the reinforced region of the shell, i.e., shells $\mathrm{C} 5$, C6, and C9-C15 (see initial buckling deformations in Fig 18a for shell C5). In addition, the initial buckling event in these shells with thicker reinforcement are typically characterized by a single, small-magnitude, ellipse-shaped buckle that forms at the edge of the reinforcement region. This lack of symmetry in the initial buckling deformations is attributed to the effects of initial geometric imperfections, and this response agrees well with the corresponding predicted results. For example, predicted initial buckling displacements contours are shown in Fig. 22a, 22b, and 22c, for imperfect shells C13, C9, and C15, with 2.4-in.-square, 4.4-in.-square, and 8.0-in.-square, 90 reinforcement configurations, respectively. For all cases, the results indicate a localized buckling response that occurs near the edge of the reinforcement region in the shell. Shells with unreinforced cutouts can exhibit a stable post-local buckling equilibrium and can sustain additional axial load until global collapse occurs in the shell (e.g., see shells $\mathrm{C} 1$ and $\mathrm{C} 2$ in Fig. 7). The results indicated that, in all shells with reinforced cutouts, the local buckling response in the shell caused a disturbance in the shell with enough kinetic energy to cause the immediate global collapse to occur in the shell. The results also indicate that unreinforced shells and shells with 1-ply-thick and 2ply-thick reinforcements exhibit interlaminar shear failures at the free edge of the cutout that are caused by largemagnitude bending gradients that develop near the cutout in the postbucking range of loading. The shells with $90^{\circ}-$ ply reinforcements always exhibited more local damage near the cutout, as compared to the corresponding shell with $0^{\circ}$-ply reinforcement. In contrast, the shells with 4-ply-thick reinforcements do not sustain damage near the cutout because the reinforcement significantly reduces the magnitude of the local bending deformations near the cutout that typically activate the interlaminar failures seen in the other shells. Rather, damage occurs in these shells along nodal lines between each of the inward buckles associated with the general instability deformation pattern.

\section{Concluding Remarks}

Results from a numerical and experimental study of the response of compression-loaded, laminated-composite, cylindrical shells with either reinforced or unreinforced cutouts have been presented. The numerical results were obtained by using high-fidelity nonlinear finite-element analyses. The analysis accounted for the effects of initial geometric imperfections, shell-wall thickness variations, material property variations, and nonuniform load introduction effects. In addition, preliminary results from a progressive failure analysis for predicting intralaminar and interlaminar material failures are presented. The results identify some of the effects of cutout-reinforcement orthotropy, size, and thickness on the buckling and failure response of the shells.

In general, the addition of reinforcement around a cutout in a compression-loaded shell can have a significant effect on the shell response. Results have been presented that indicate that the reinforcement can affect the local shell-wall deformations and strains near the cutout and retard or suppress the onset of local buckling and failure in the shell near the cutout. For some cases, the local buckling response near the cutout in the shell results in a stable post-local-buckling response near the cutout and additional load can be applied to the shell before it undergoes global collapse. For other cases, the local response near the cutout in the shell cause a disturbance in the shell with enough kinetic energy to cause the global collapse of the shell immediately following the local instability. For still other cases, the reinforcement suppresses the local buckling response near the cutout and causes buckling to occur at the edge of the reinforcement region in the shell. In general, the buckling load of the shell increases as the size and 
the thickness of the reinforcement increases. The results also indicate that shells with $90^{\circ}$-ply cutout reinforcement generally have higher buckling loads than the corresponding shells with $0^{\circ}$-ply reinforcements. The results indicate that the shells with unreinforced, and some with reinforced, cutouts exhibit large-magnitude displacements and bending strains near the cutout and that these deformations and strains activate an interlaminar shear failure mechanism in the shell. Furthermore, shells with $90^{\circ}$-ply cutout reinforcement typically exhibit significantly larger amounts of interlaminar damage accumulation near the cutout than the corresponding shells with $0^{\circ}$-ply reinforcements.

The selected results presented herein suggest that tailoring the orthotropy, thickness, and size of the cutout reinforcement in a compression-loaded shell can results in significant increases in the buckling load of the shell, and can reduce the local deformations, strains, and damage accumulation near the cutout. The robust validated highfidelity nonlinear analysis procedure used in this study offers the opportunity to provide insight into various cutout reinforcement concepts on the buckling and failure response of compression-loaded shell structures. Moreover, results from such a high-fidelity analysis procedure can improve some of the engineering approximatins and methods that are used in the design of composite shell structures with cutouts.

\section{Acknowledgment}

The authors would like to dedicate this paper to the memory of the late Dr. James H. Starnes, Jr. of the NASA Langley Research Center. Dr. Starnes was an internationally recognized expert in structural mechanics and aerospace structures technology. He was also a renowned technical leader and a dedicated public servant. He is greatly remembered at NASA Langley for his exemplary service, positive attitude, and friendly interactions with colleagues. Dr. Starnes was particularly recognized by his employees as an exceptional supervisor, mentor, and technical leader. He routinely demonstrated great technical breadth and depth, enthusiasm, and a willingness to listen to other views. In addition, he was masterful at motivating his employees to make contributions that far exceeded their own expectations. He gained the respect of everyone whose life he touched and he profoundly influenced the careers and lives of many, including the authors'.

\section{References}

1. Starnes, J. H., Jr., Hilburger, M. W., and Nemeth, M. P., "The Effects of Initial Imperfections on the Buckling of Composite Shells," Composite Structures: Theory and Practice, ASTM STP 1383, P. Grant and C. Q. Rousseau, Eds., American Society for Testing and Materials, 2000, pp. 529-550.

2. Hilburger, M. H., and Starnes, J. H., Jr., "Effects of Imperfections on the Buckling Response of Compression-loaded Composite Shells," International Journal of Non-linear Mechanics, Vol. 37, 2002, pp. 623-643.

3. Hilburger, M. W., and Nemeth, M. P., and Starnes, J. H., Jr., "Shell Buckling Design Criteria Based on Manufacturing Imperfection Signatures," NASA/TM-2004-212659, May, 2004.

4. Tennyson, R. C., "The Effects of Unreinforced Circular Cutouts on the Buckling of Circular Cylindrical Shells," Journal of Engineering for Industry, Transactions of the American Society of Mechanical Engineers, Vol. 90, November 1968, pp. $541-546$.

5. Brogan, F. A. and Almroth, B. O., "Buckling of Cylinders with Cutouts," AIAA Journal, Vol. 8, No. 2, February 1970, pp. 236-240.

6. Starnes, J. H., Jr., "The Effect of a Circular Hole on the Buckling of Cylindrical Shells," Ph. D. Dissertation, California Institute of Technology, Pasadena, California, 1970.

7. Jenkins, W. C., "Buckling of Cylinders with Cutouts under Combined Loading," MDC Report G2476, October 1971, McDonnell-Douglas Astronautics Co.

8. Almroth, B. O. and Holmes, A. M. C., "Buckling of Shells with Cutouts, Experiment and Analysis," International Journal of Solids and Structures, Vol. 8, 1972, pp. 1057-1071.

9. Starnes, J. H., Jr., "Effect of a Slot on the Buckling Load of a Cylindrical Shell with a Circular Cutout, " AIAA Journal, Vol. 10, No. 2, February 1972, pp. 227-229.

10. Almroth, B. O., Brogan, F. A., and Marlowe, M. B., "Stability Analysis of Cylinders with Circular Cutouts," AIAA Journal, Vol. 11, No. 11, 1973, pp. 1582-1584.

11. Starnes, J. H., Jr., "The Effects of Cutouts on the Buckling of Thin Shells," Thin-Shell Structures: Theory, Experiment, and Design, edited by Y. C. Fung and E. E. Sechler, Prentice-Hall, Inc., Englewood Cliffs, New Jersey, 1974, pp. $289-304$.

12. Almroth, B. O., Meller, E, and Brogan, F. A., "Computer Solutions for Static and Dynamic Buckling of Shells," Buckling of Structures, edited by B. Budiansky, IUTAM Symposium, Cambridge, Massachusetts, 1974, pp. 52-66.

13. Toda, S, "Buckling of Cylinders with Cutouts Under Axial Compression," Experimental Mechanics, Vol. 3, 1983, pp. 414-417.

14. Janisse, T. C. and Palazotto, A. N., "Collapse Analysis of Composite Panels With Cutouts," Proceedings of the AIAA/ASME/ASCE/AHS 24th Structures, Structural Dynamics, and Materials Conference, AIAA paper 83-0875, 1983. 
15. Knight, N. F. and Starnes, J. H., Jr., "Postbuckling Behavior of Selected Graphite-Epoxy Cylindrical Panel Loaded in Compression," Proceedings of the AIAA/ASME/ASCE/AHS 27th Structures, Structural Dynamics, and Materials Conference, AIAA paper 86-0881-CP, 1986.

16. Knight, N. F. and Starnes, J. H., Jr., "Postbuckling Behavior of Axially Compressed Graphite-Epoxy Cylindrical Panels with Circular Holes," Proceedings of the 1984 ASME Joint Pressure Vessels and Piping/Applied Mechanics Conference, 1984.

17. Lee, C. E. and Palazotto, A. N., "Nonlinear Collapse Analysis of Composite Cylindrical Panels With Small Cutouts or Notches," Proceedings of the AIAA/ASME/ASCE/AHS 25th Structures, Structural Dynamics, and Materials Conference, AIAA paper 84-0889, 1984.

18. Madenci, E. and Barut, A., "Pre- and Postbuckling Response of Curved, Thin, Composite Panels with Cutouts Under Compression, International Journal for Numerical Methods in Engineering, Vol. 37, 1994, pp. 1499-1510.

19. Hilburger, M. W., "Numerical and Experimental Study of the Compression Response of Composite Cylindrical Shells with Cutouts," Ph. D. Dissertation, University of Michigan, Ann Arbor, Michigan, 1998.

20. Hilburger, M. W., Waas, A. M., and Starnes, J. H., Jr., "Response of Composite Shells with Cutouts Subjected to Internal Pressure and Compression Loads," AIAA Journal, Vol. 32, No. 2, 1999, pp. 232-237.

21. Hilburger, M. W., Starnes, J. H., Jr., and Waas, A. M. "A Numerical and Experimental Study of the Response of Selected Compression-loaded Composite Shells with Cutouts," Proceedings of the 39th AIAA/ASME/ASCE/AHS/ASC Structures, Structural Dynamics, and Materials Conference, Long Beach, CA, AIAA Paper No. 98-1768, 1998.

22. Jullien, J. F. and Limam, A., "Effects of Openings on the Buckling of Cylindrical Shells Subjected to Axial Compression, Thin-Walled Structures, Vol. 31, 1998, pp. 187-202.

22. Nemeth, M. P. and Starnes, J. H., Jr., "The NASA Monographs on Shell Stability Design Recommendations: A Review and Suggested Improvements, NASA/TP-1998-206290, January 1998.

23. Hilburger, M. W., Britt, V. O., and Nemeth, M. P., "Buckling Behavior of Compression-Loaded Quasi-Isotropic Curved Panels with a Circular Cutout, ," International Journal of Solids and Structures, Vol. 38, 2001, pp. 1495-1522.

24. Tafreshi, A., "Buckling and Post-buckling Analysis of Composite Cylindrical Shells with Cutouts Subjected to Internal Pressure and Axial Compression Loads," International Journal of Pressure Vessels and Piping, Vol. 79, 2002, pp. 351-359.

25. Madenci, E. and Barut, A., "The Influence of Geometric Irregularities on the Linear Buckling of Cylindrical Shells with an Elliptical Cutout," Proceedings of the 44th AIAA/ASME/ASCE/AHS/ASC Structures, Structural Dynamics, and Materials Conference, Norfolk, VA. AIAA Paper No. 2003-1929, 2003.

26. Cervantes, J. A. and Palazotto, A. N., "Cutout Reinforcement of Stiffened Cylindrical Shells," Journal of Aircraft, Vol. 16, No. 3, 1979, pp. 203-208.

27. Hilburger, M. W., and Starnes, J. H., Jr., "Bucking of Compression-loaded Composite Cylindrical Shells with Reinforced Cutouts," Proceedings of the AIAA/ASME/ASCE/AHS/ASC 43rd Structures, Structural Dynamics, and Materials Conference, Denver, CO. AIAA Paper No. 2002-1516, 2002.

28. Hilburger, M. W., and Starnes, J. H., Jr., "Bucking of Compression-loaded Composite Cylindrical Shells with Reinforced Cutouts," NASA/TM-2004-212656, September 2004.

29. Jaunky, N., Ambur, D. R., Davila, C. G., and Hilburger, M. W., "Progressive Failure Studies of Composite Panels with and without Cutouts," NASA/CR-2001-211223, September 2001.

30. Vinay, K. G., Jaunky, N., Johnson, E. R., and Ambur, D. R., "Intralaminar and Interlaminar Progressive Failure Analyses of Composite Panels with Circular Cutouts," Proceedings of the AIAA/ASME/ASCE/AHS/ASC 43rd Structures, Structural Dynamics, and Materials Conference, Denver, CO. AIAA Paper No. 2002-1745, 2002.

31. Rankin, C. C., Brogan, F. A., Loden, W. A., and Cabiness, H. D., "STAGS Users Manual, Version 5.0," Lockheed Martin Missiles \& Space Co., Inc., Advance Technology Center, Report LMSC P032594, 2005.

32. Hashin, Z., "Failure Criteria for Unidirectional Fiber Composites," Journal of Applied Mechanics, 47, 1980, pp. 329-334.

33. Chang, F. K., and Lessard, L., "Damage Tolerance of Laminated Composites Containing an Open Hole and Subjected to Compressive Loadings: Part I - Analysis," Journal of Composite Materials, 25, 1991, pp. 2-43. 
Table 1: Predicted and measured normalized buckling loads $\left(P_{c r}{ }^{o}=42,590 \mathrm{lb}\right.$ is the corresponding linear bifurcation buckling load of a geometrically perfect quasi-isotropic cylinder).

\begin{tabular}{|c|l|c|c|c|}
\hline $\begin{array}{c}\text { Specimen } \\
\text { number }\end{array}$ & $\begin{array}{c}\text { Shell-wall laminate / } \\
\text { reinforcement size (in.) } / \\
\text { reinforcement lay-up }\end{array}$ & $\begin{array}{c}\text { Predicted } \\
\text { buckling load } \\
\text { imperfect shell), } \\
P_{c r}{ }^{i m p} / P_{c r}{ }^{o}\end{array}$ & $\begin{array}{c}\text { Measured } \\
\text { buckling } \\
\text { load, } \\
P_{c r} / P_{c r}{ }^{o}\end{array}$ & $\begin{array}{c}\text { Difference between } \\
\text { measured and } \\
\text { predicted buckling } \\
\text { loads, \% }\end{array}$ \\
\hline \hline $\mathrm{C} 1$ & {$[\mp 45 / 0 / 90]_{\mathrm{s}} /$ none } & 0.51 & 0.48 & 6.3 \\
\hline $\mathrm{C} 2$ & {$\left[\mp 45 / 0_{2}\right]_{\mathrm{s}} /$ none } & 0.40 & 0.40 & 2.6 \\
\hline $\mathrm{C} 3$ & {$\left[\mp 45 / 90_{2}\right]_{\mathrm{s}} /$ none } & 0.50 & 0.51 & 9.8 \\
\hline $\mathrm{C} 4$ & {$[\mp 45 / 0 / 90]_{\mathrm{s}} / 4.4 / 0_{1}$} & 0.68 & 0.67 & 1.5 \\
\hline $\mathrm{C} 5$ & {$[\mp 45 / 0 / 90]_{\mathrm{s}} / 4.4 / 0_{2}$} & 0.78 & 0.74 & 5.4 \\
\hline $\mathrm{C} 6$ & {$[\mp 45 / 0 / 90]_{\mathrm{s}} / 4.4 / 0_{4}$} & 0.80 & 0.75 & 6.7 \\
\hline $\mathrm{C} 7$ & {$[\mp 45 / 0 / 90]_{\mathrm{s}} / 4.4 / 90_{1}$} & 0.76 & 0.75 & 1.3 \\
\hline $\mathrm{C} 8$ & {$[\mp 45 / 0 / 90]_{\mathrm{s}} / 4.4 / 90_{2}$} & 0.76 & 0.76 & 0.0 \\
\hline $\mathrm{C} 9$ & {$[\mp 45 / 0 / 90]_{\mathrm{s}} / 4.4 / 90_{4}$} & 0.80 & 0.75 & 6.7 \\
\hline $\mathrm{C} 10$ & {$[\mp 45 / 0 / 90]_{\mathrm{s}} / 2.4 / 0_{2}$} & 0.72 & 0.71 & 1.4 \\
\hline $\mathrm{C} 11$ & {$[\mp 45 / 0 / 90]_{\mathrm{s}} / 2.4 / 0_{4}$} & 0.76 & 0.73 & 4.1 \\
\hline $\mathrm{C} 12$ & {$[\mp 45 / 0 / 90]_{\mathrm{s}} / 2.4 / 90_{2}$} & 0.72 & 0.72 & 0.0 \\
\hline $\mathrm{C} 13$ & {$[\mp 45 / 0 / 90]_{\mathrm{s}} / 2.4 / 90_{4}$} & 0.73 & 0.76 & 3.9 \\
\hline $\mathrm{C} 14$ & {$[\mp 45 / 0 / 90]_{\mathrm{s}} / 8.0 / 0_{4}$} & 0.73 & 0.71 & 2.8 \\
\hline $\mathrm{C} 15$ & {$[\mp 45 / 0 / 90]_{\mathrm{s}} / 8.0 / 90_{4}$} & 0.79 & 0.75 & 5.3 \\
\hline
\end{tabular}

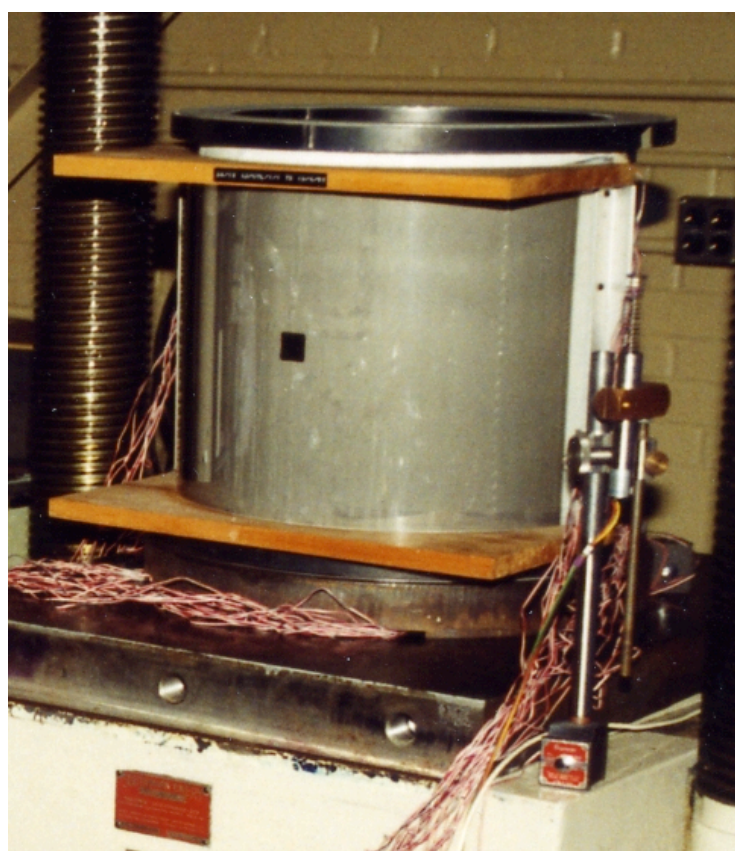

a) Front view

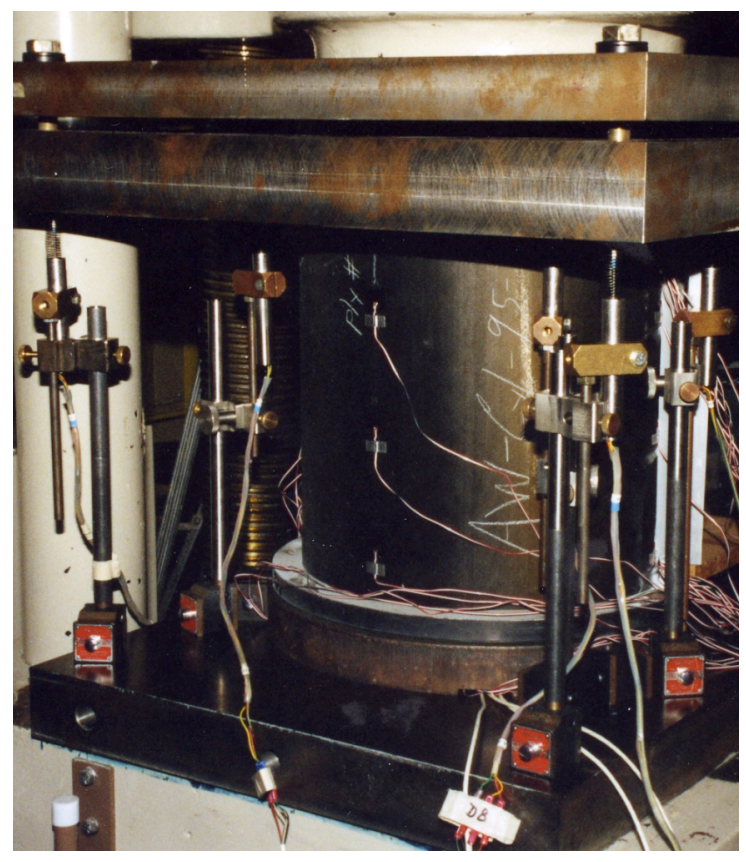

b) Rear view

Fig. 1 Typical test set-up for a compression-loaded composite cylinder with a cutout. 


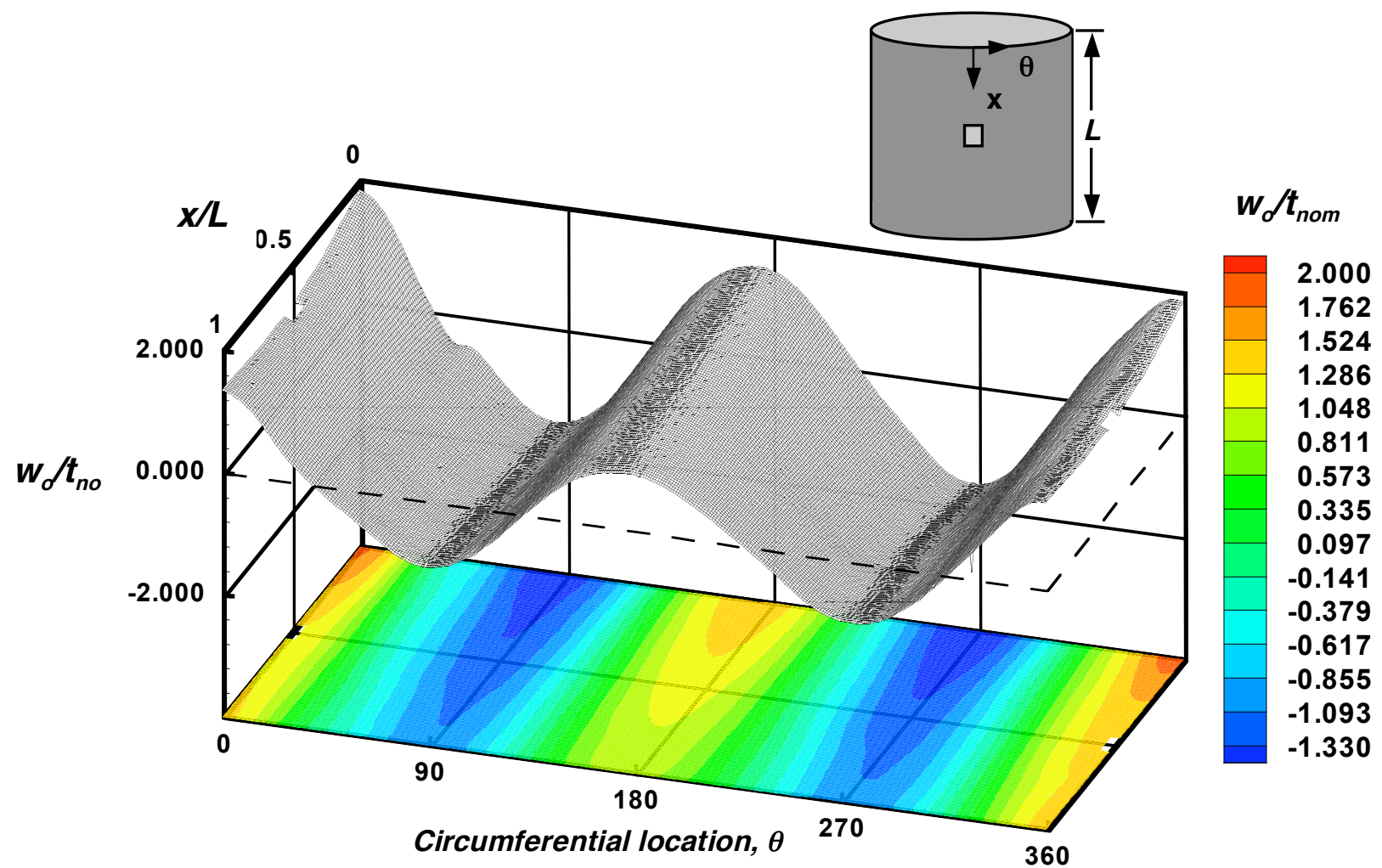

Fig. 2 Typical measured initial geometric imperfection for a composite cylinder with a cutout.

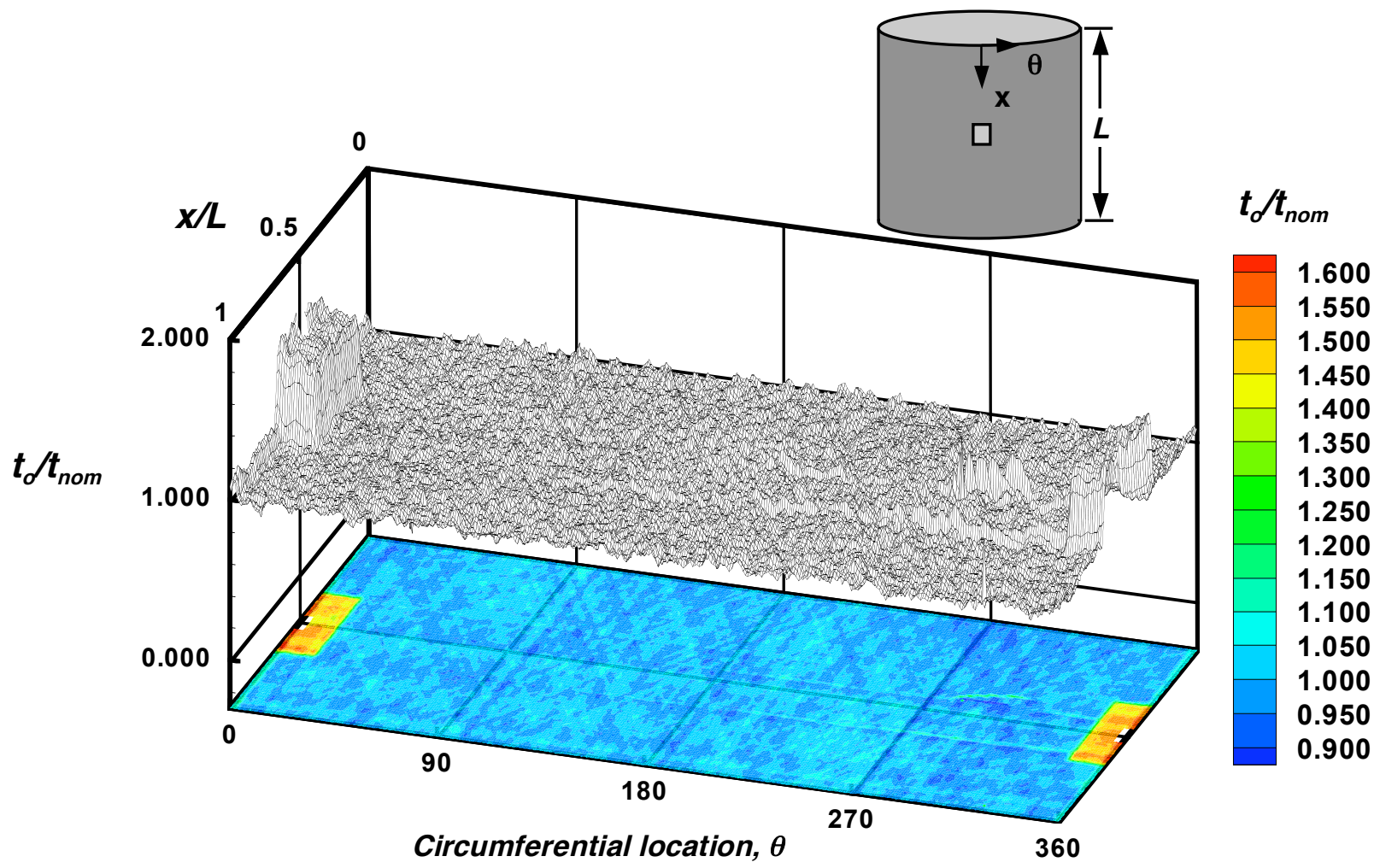

Fig. 3 Typical measured shell-wall thickness variation for a composite cylinder with a reinforced cutout. 

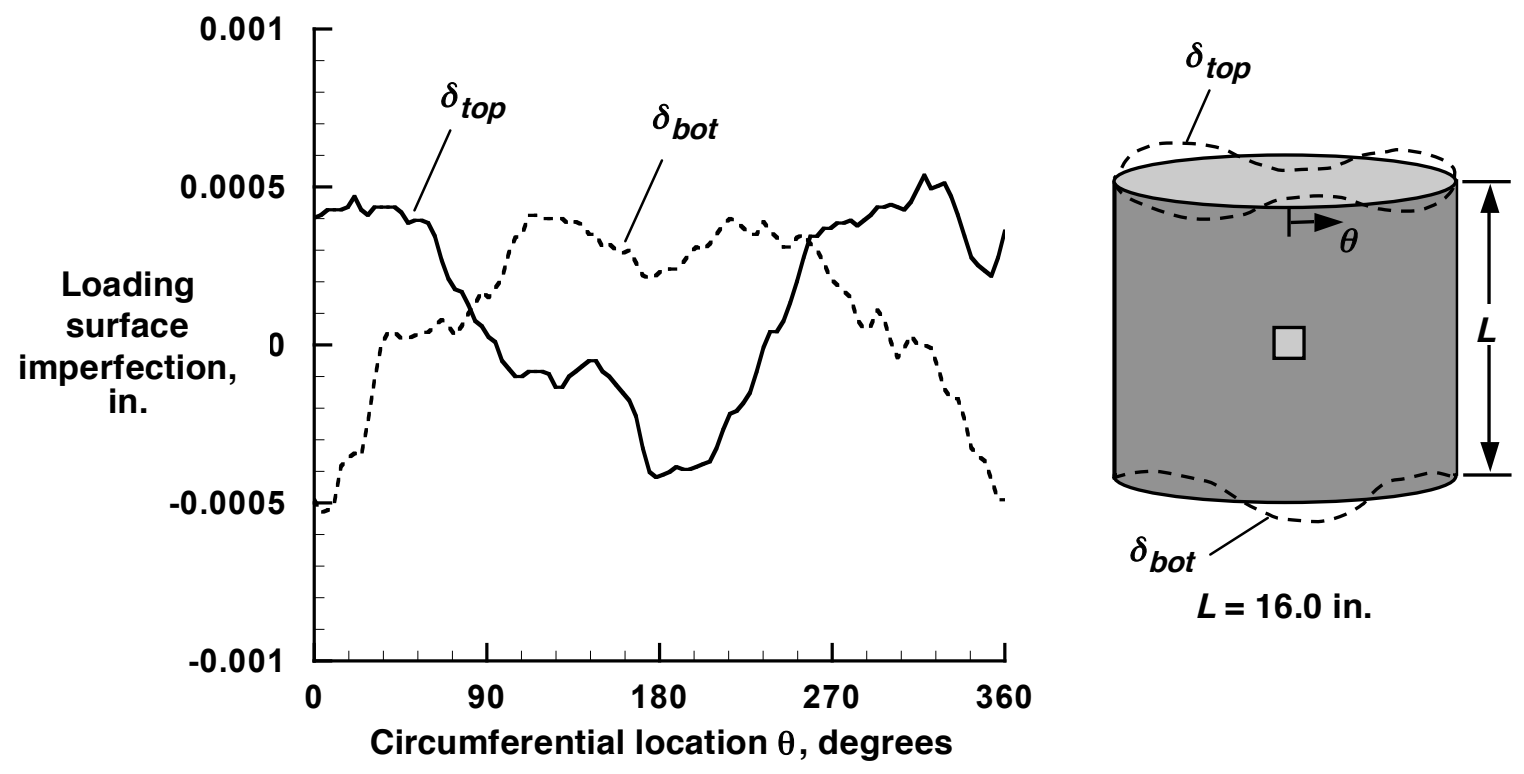

Fig. 4 Typical measured shell-end or loading-surface imperfections for a composite cylinder specimen.

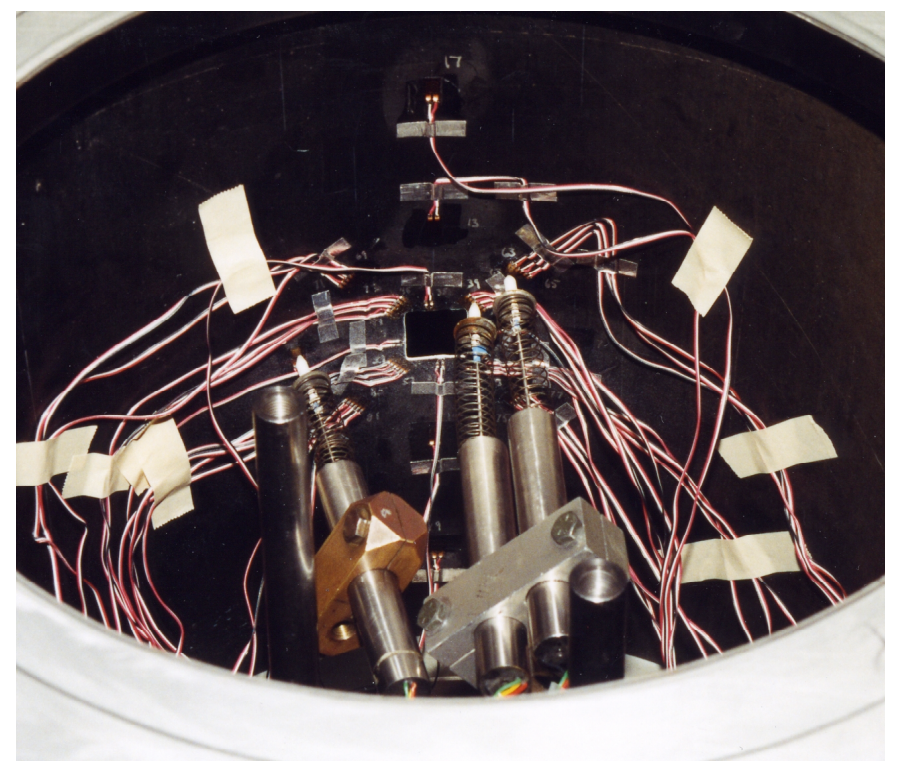

a) Internal strain gages and DCDTs

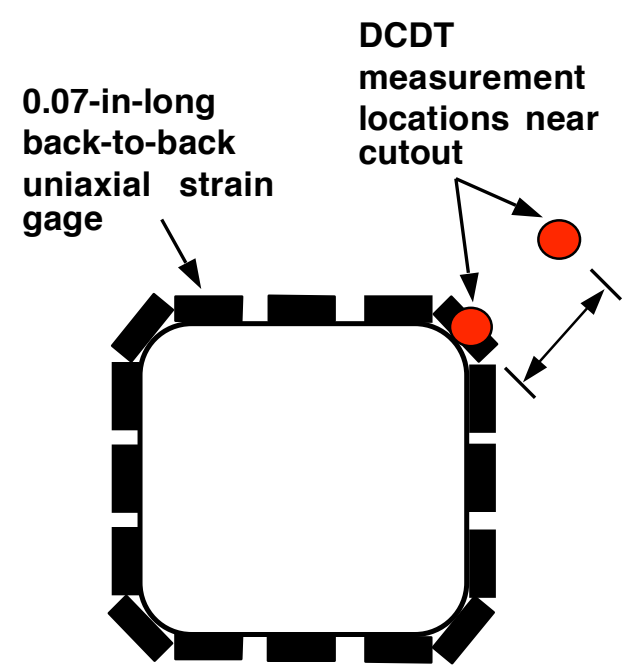

b) Instrumentation pattern near cutout

Fig. 5 Typical DCDT and strain gage instrumentation near the cutout. 


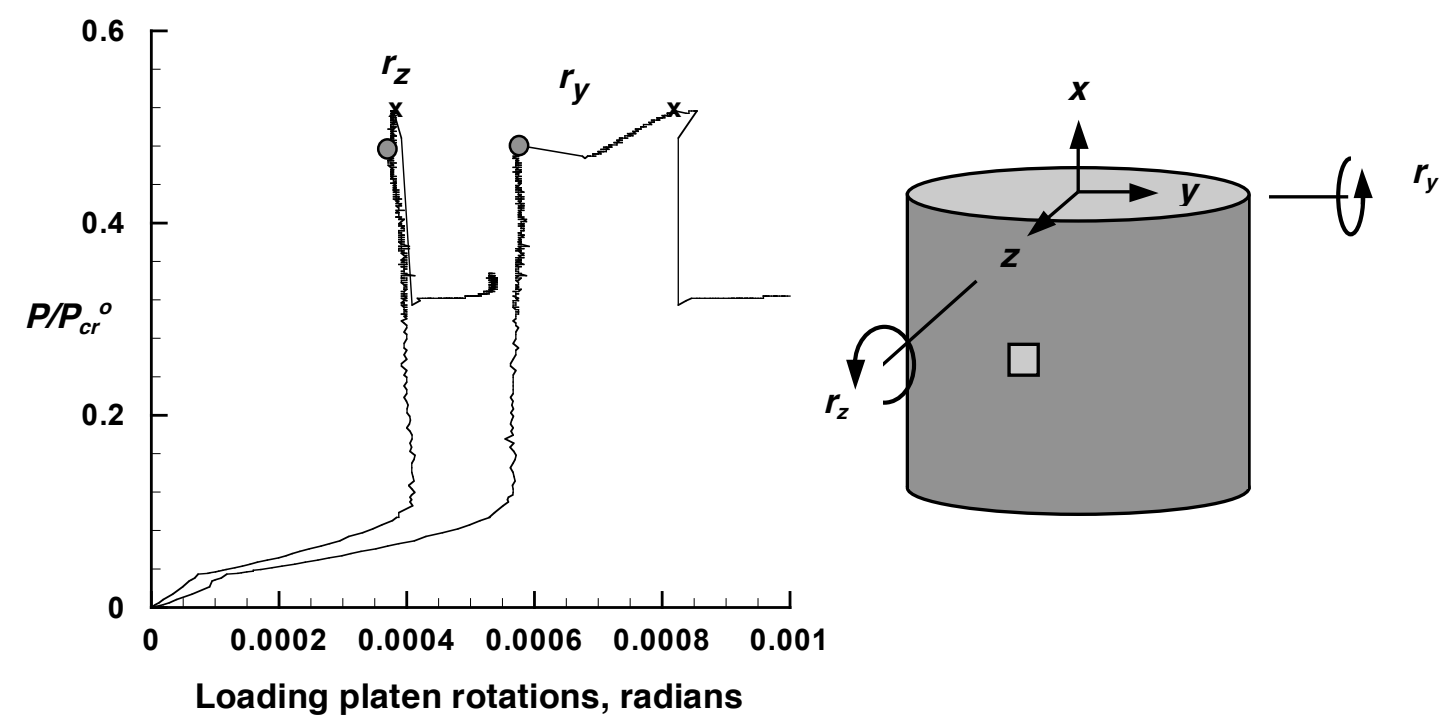

Fig. 6 Measured loading platen rotations for a compression-loaded composite cylinder with a 1-in. by 1-in. square cutout $\left(\mathrm{P}_{\mathrm{cr}}{ }^{\circ}=42,590 \mathrm{lb}\right.$ is the predicted linear bifurcation buckling load of the corresponding geometrically perfect quasi-isotropic shell without a cutout).

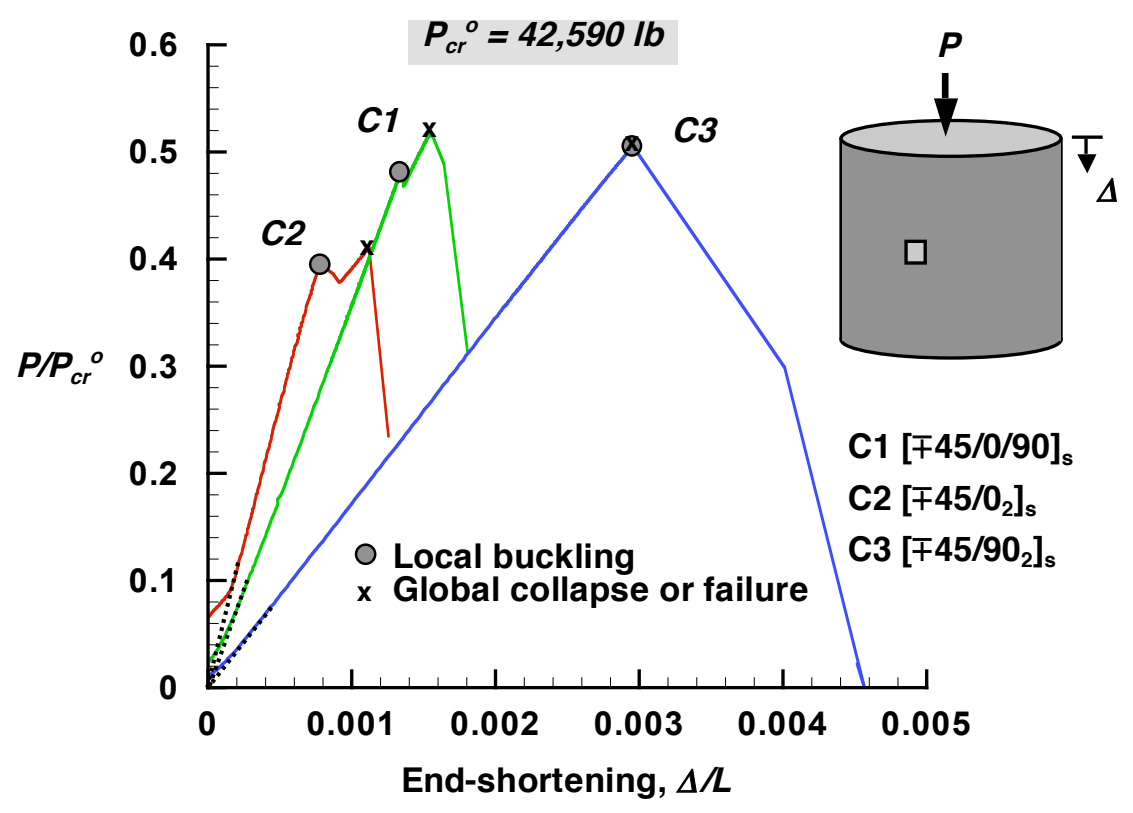

Fig. 7 Load-shortening response curves for compression-loaded composite cylinders with unreinforced 1-in. by 1in. square-shaped cutouts $\left(\mathrm{P}_{\mathrm{cr}}{ }^{\circ}=42,590 \mathrm{lb}\right.$ is the linear bifurcation buckling load of the corresponding geometrically perfect quasi-isotropic shell without a cutout). 


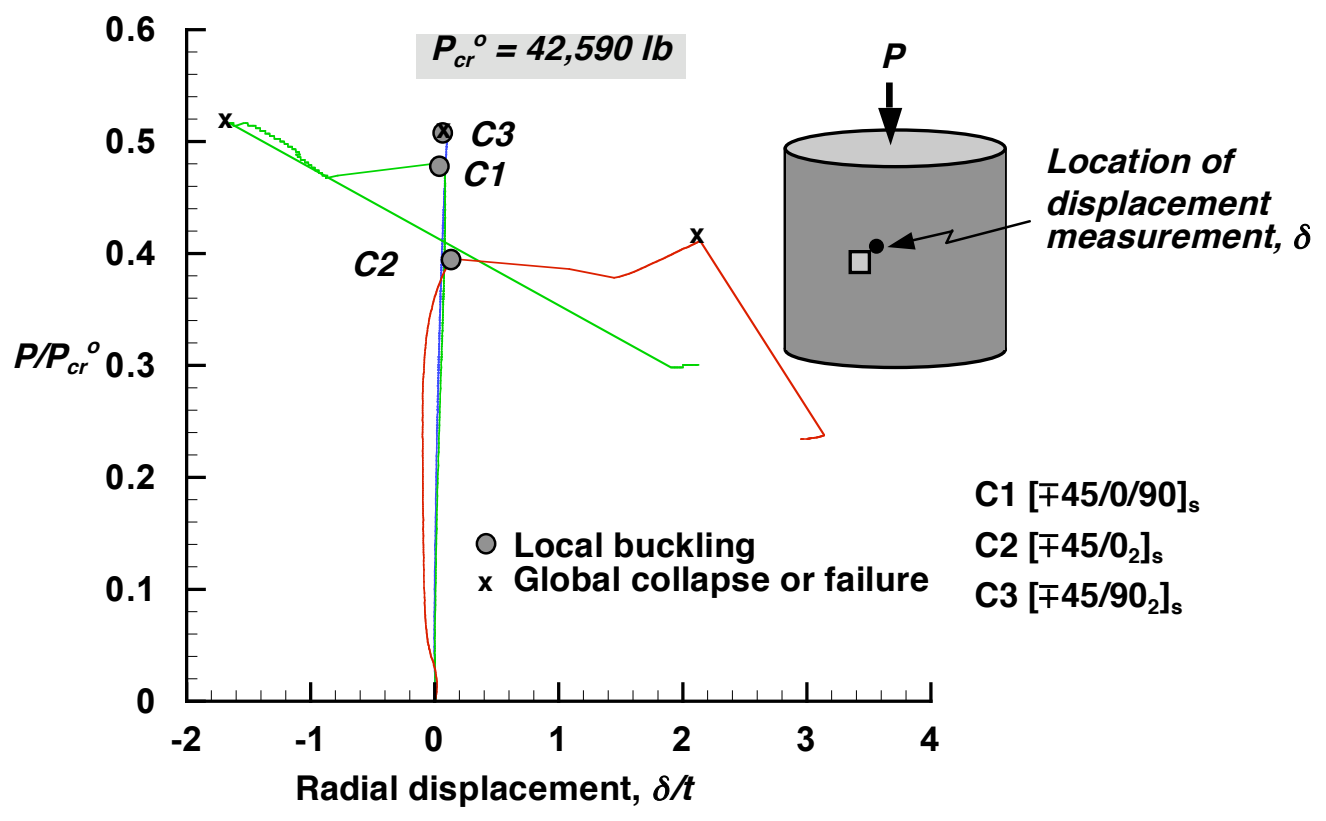

Fig. 8 Radial displacement response curves for compression-loaded composite cylinders with unreinforced 1-in. by 1-in. square-shaped cutouts $\left(\mathrm{P}_{\mathrm{cr}}{ }^{0}=42,590 \mathrm{lb}\right.$ is the linear bifurcation buckling load of the corresponding geometrically perfect quasi-isotropic shell without a cutout).

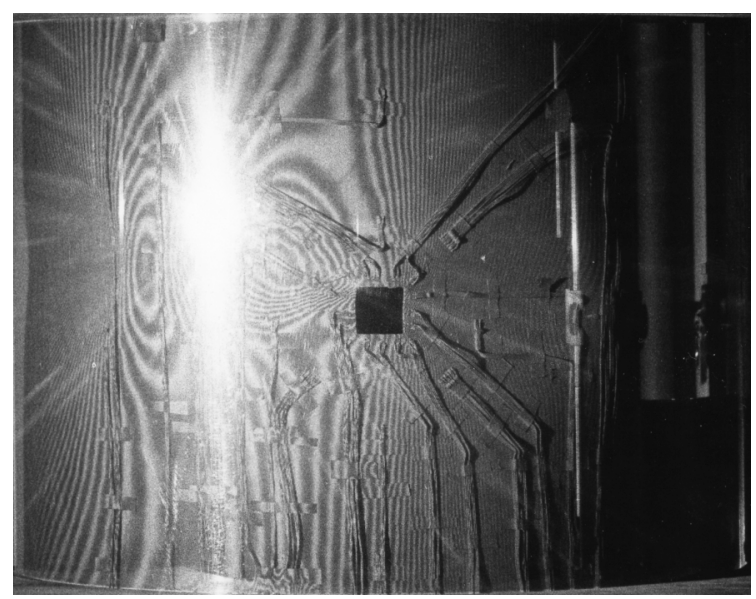

a) Local buckling moiré fringe pattern

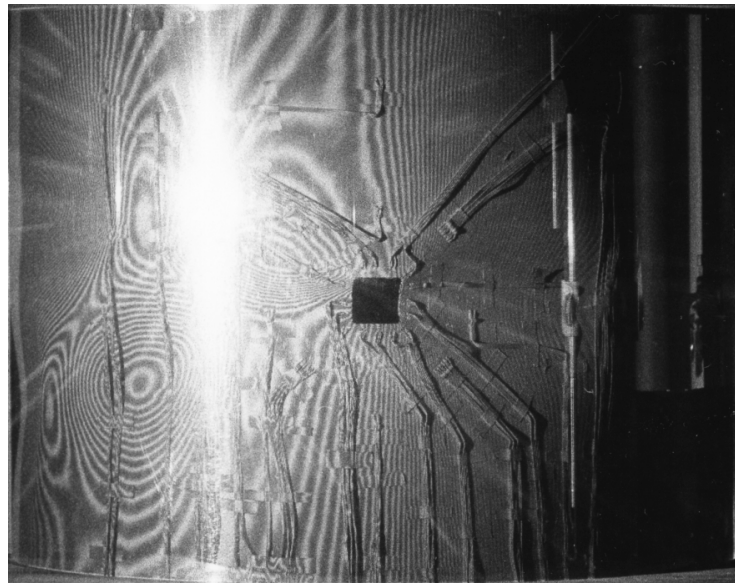

b) Global collapse moiré fringe pattern

Fig. 9 Observed radial deformation patterns near a cutout for specimen $\mathrm{C} 1$. 


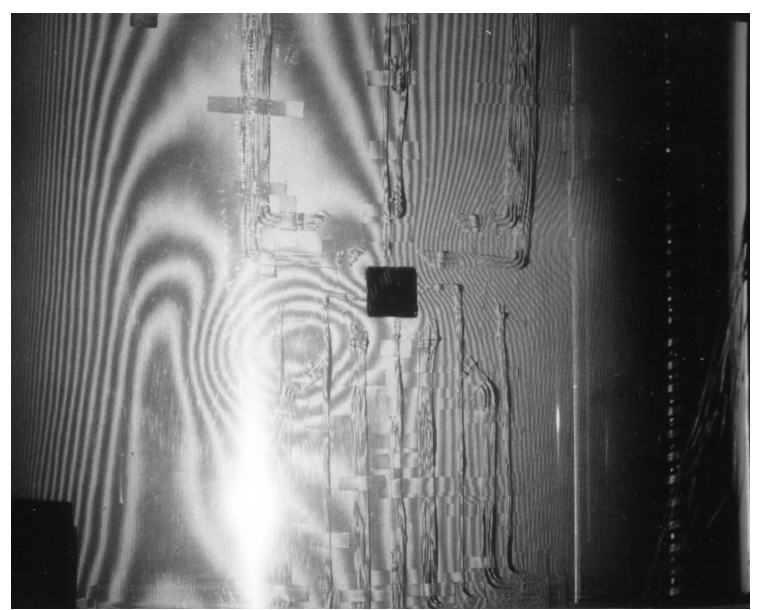

a) Local buckling moiré fringe pattern

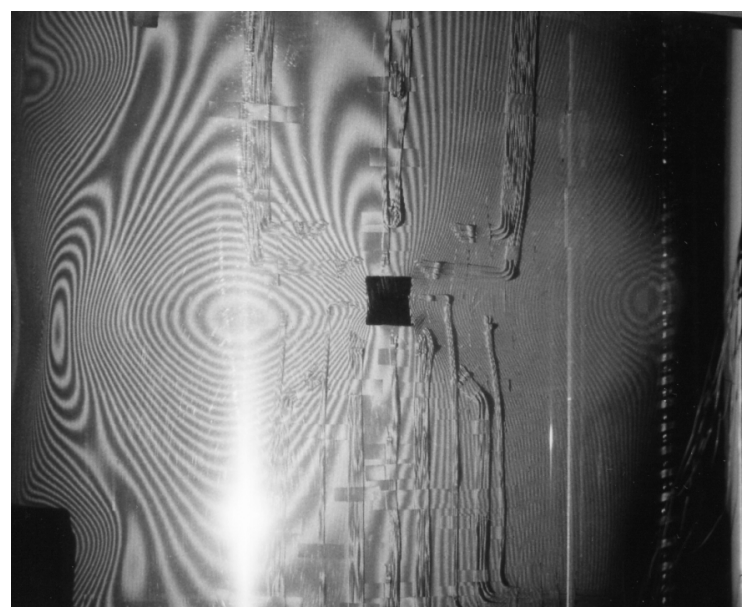

b) Global collapse moiré fringe pattern

Fig. 10 Observed radial deformation patterns near a cutout for specimen $\mathrm{C} 2$.

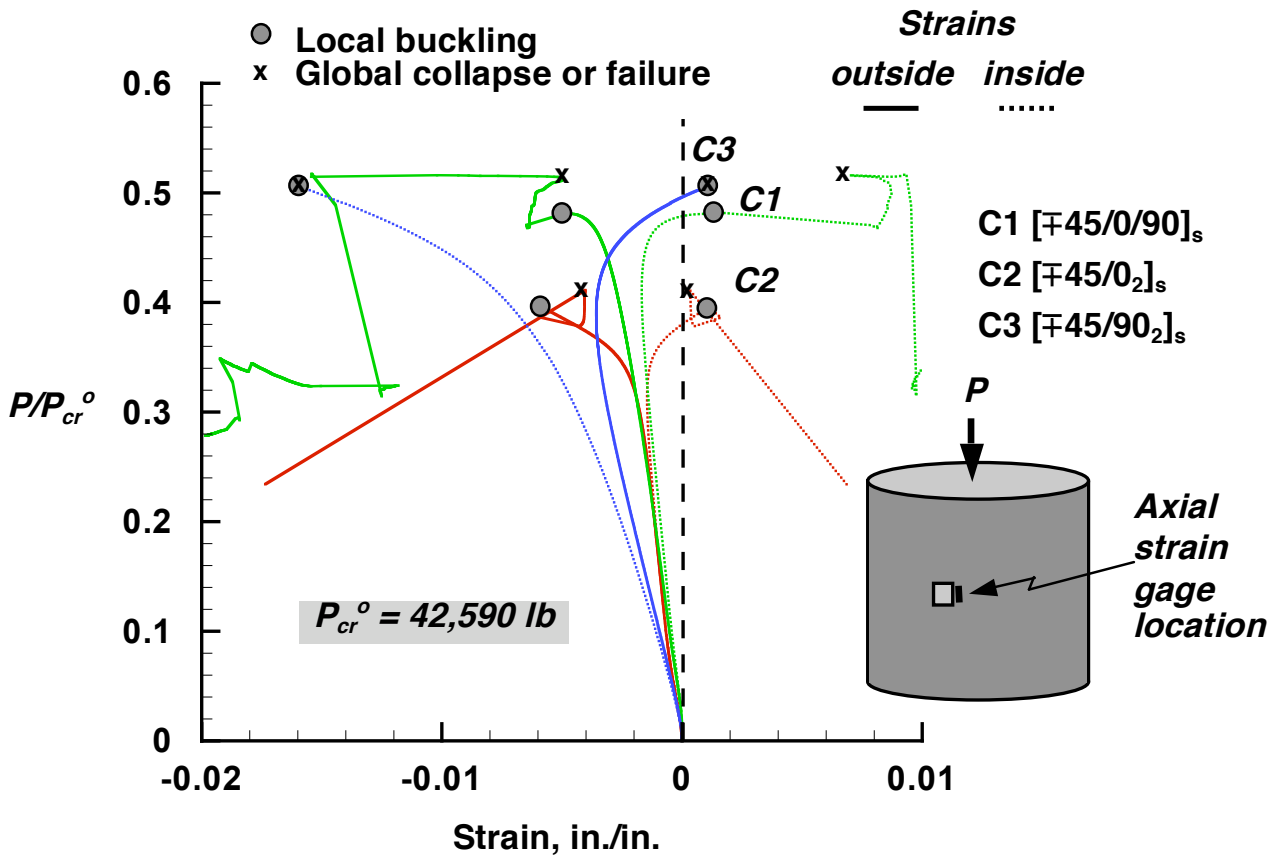

Fig. 11 Load-strain response near unreinforced 1-in. by 1-in. square-shaped cutouts in compression-loaded composite cylinders $\left(\mathrm{P}_{\mathrm{cr}}{ }^{\circ}=42,590 \mathrm{lb}\right.$ is the linear bifurcation buckling load of the corresponding geometrically perfect quasi-isotropic shell without a cutout). 


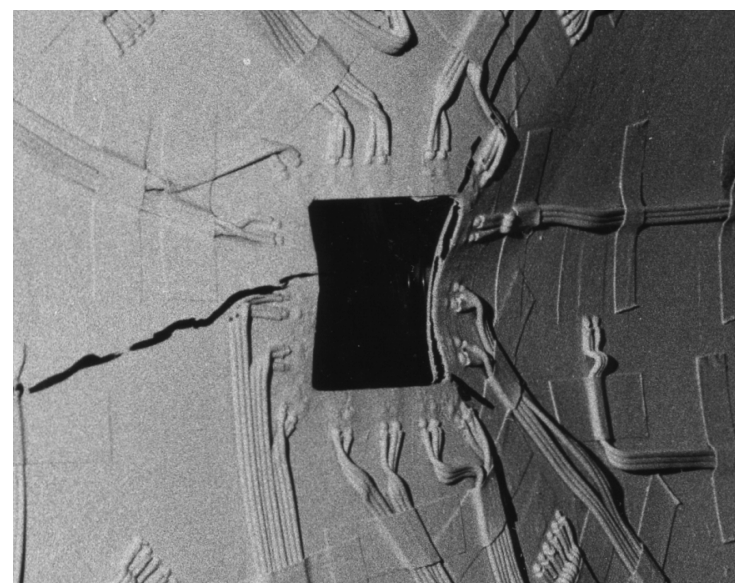

a) delamination at the right edge of the cutout

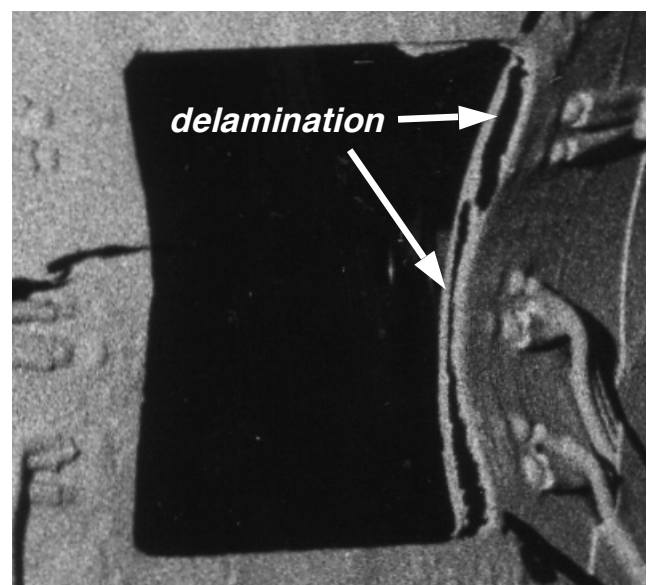

b) magnified view of cutout delamination

Fig. 12 Observed local delamination failures in specimen $\mathrm{C} 1$.

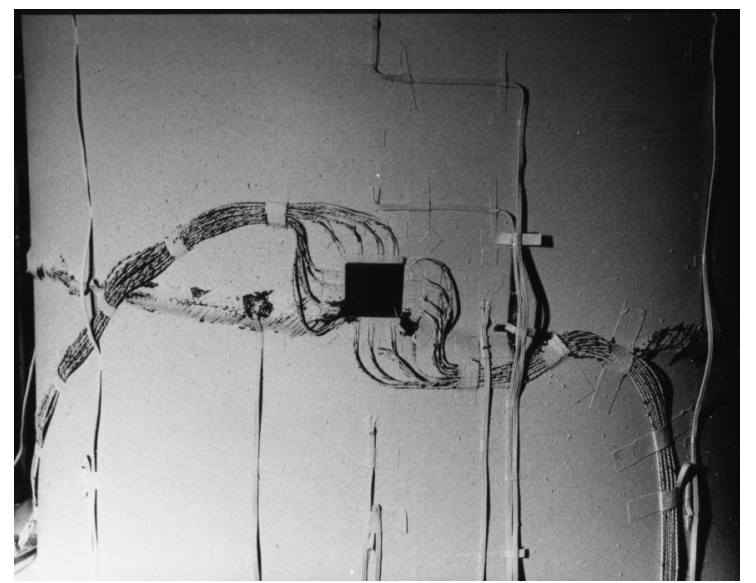

a) global view of failed specimen

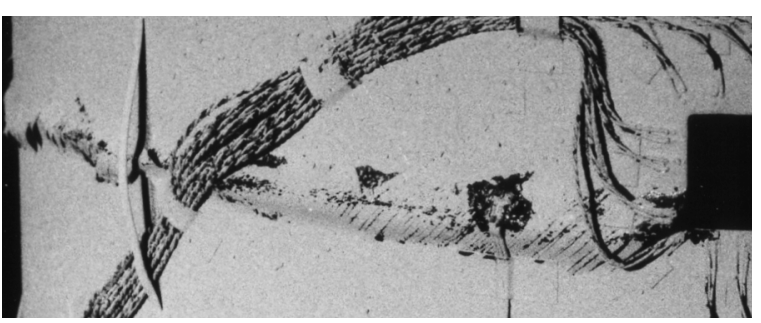

b) magnified view of delamination on left side

Fig. 13 Observed catastrophic delamination failures in specimen C3. 

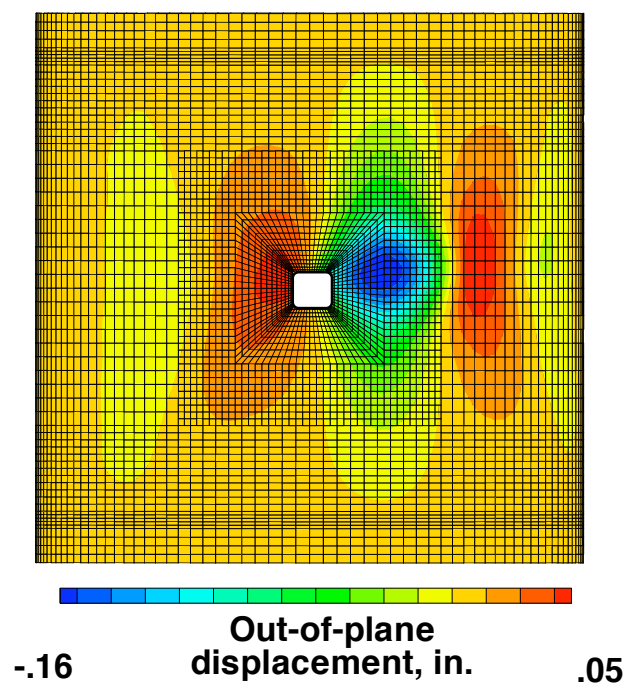

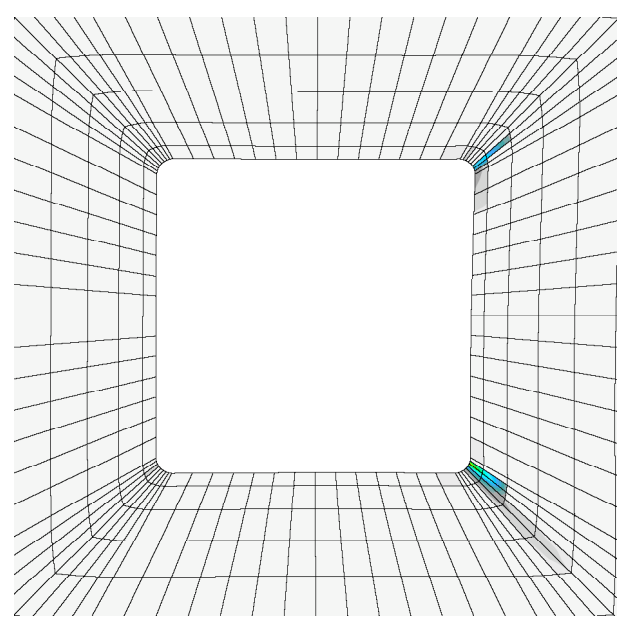

b) Intralaminar failures a) Displacement contours

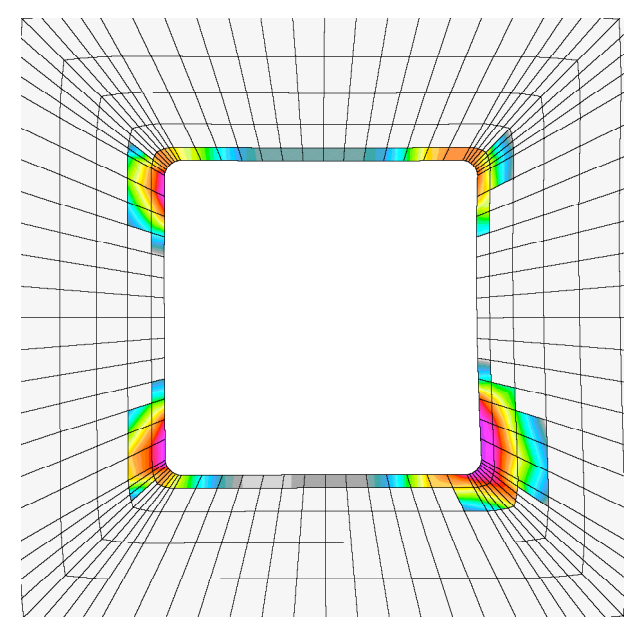

c) Interlaminar (delamination) failures

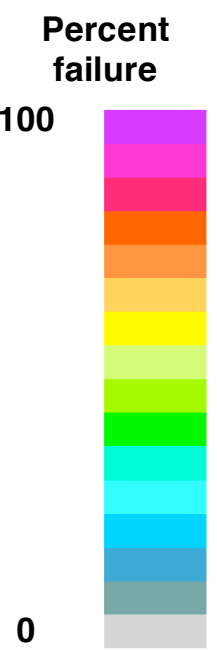

Fig. 14 Predicted local buckling displacements and material failures for specimen $\mathrm{C} 1$. 


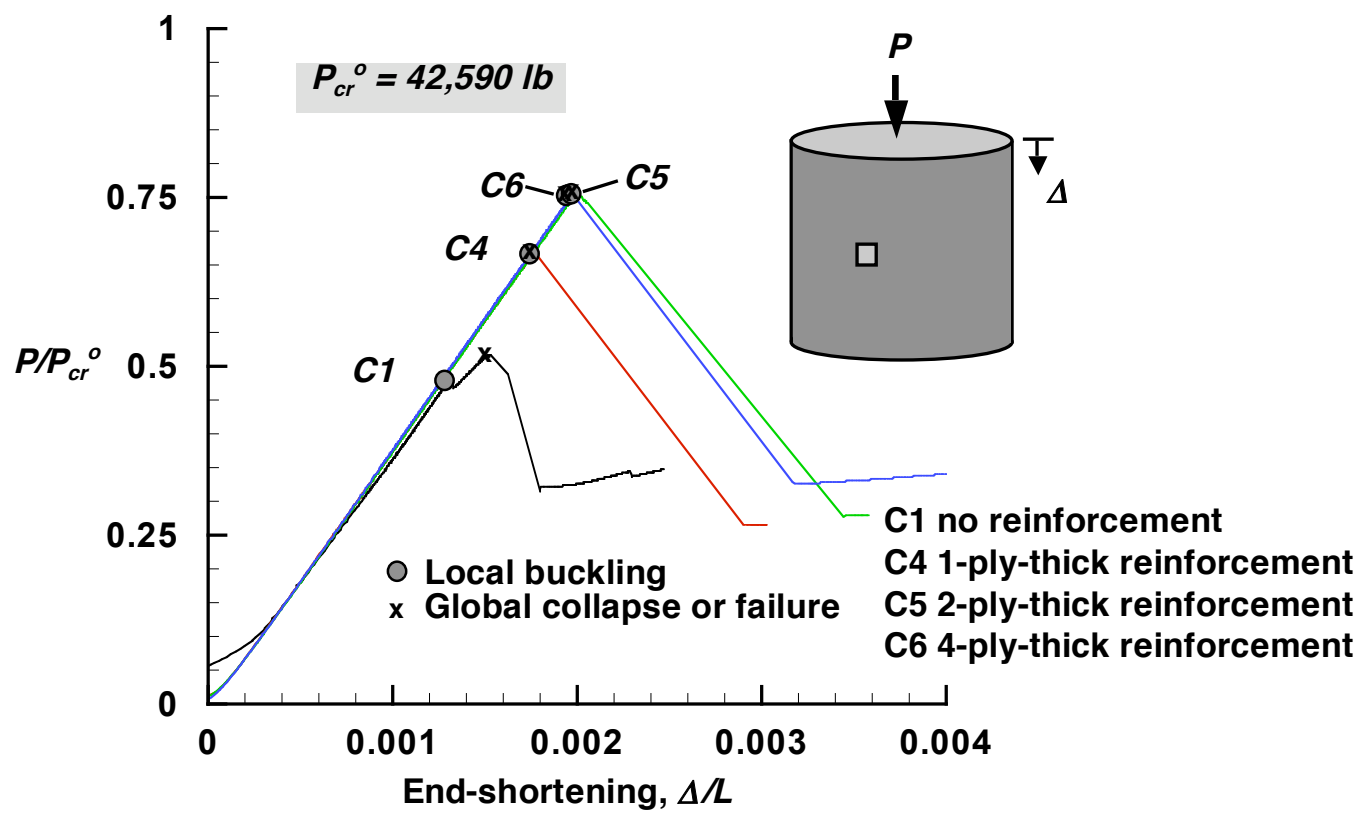

Fig. 15 Load-shortening response curves for compression-loaded quasi-isotropic cylinders with unreinforced and reinforced 1-in. by 1-in. square-shaped cutouts $\left(\mathrm{P}_{\mathrm{cr}}{ }^{\circ}=42,590 \mathrm{lb}\right.$ is the linear bifurcation buckling load of the corresponding geometrically perfect shell without a cutout).

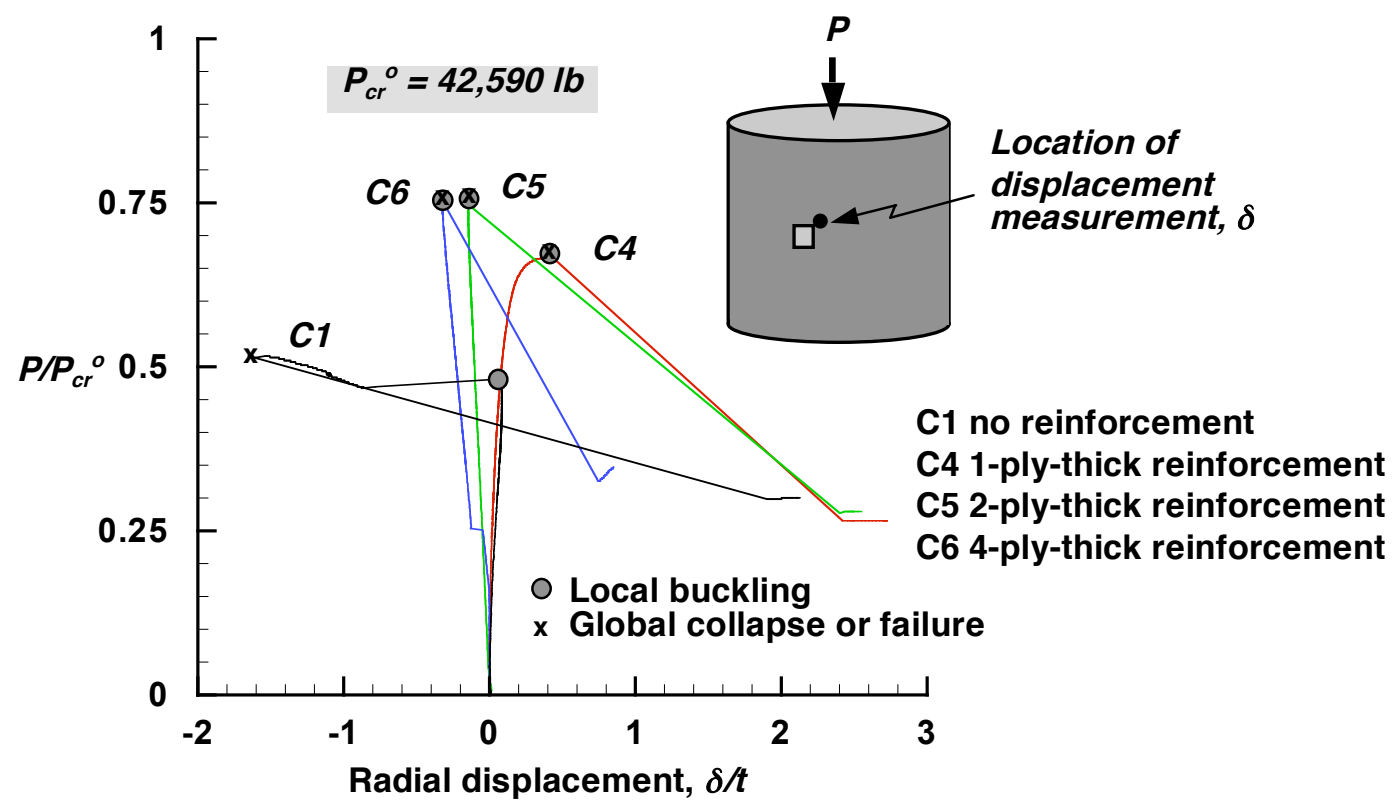

Fig. 16 Radial displacements response curves for compression-loaded quasi-isotropic cylinders with unreinforced and reinforced 1-in. by 1-in. square-shaped cutouts $\left(\mathrm{P}_{\mathrm{cr}}{ }^{\circ}=42,590 \mathrm{lb}\right.$ is the linear bifurcation buckling load of the corresponding geometrically perfect shell without a cutout). 


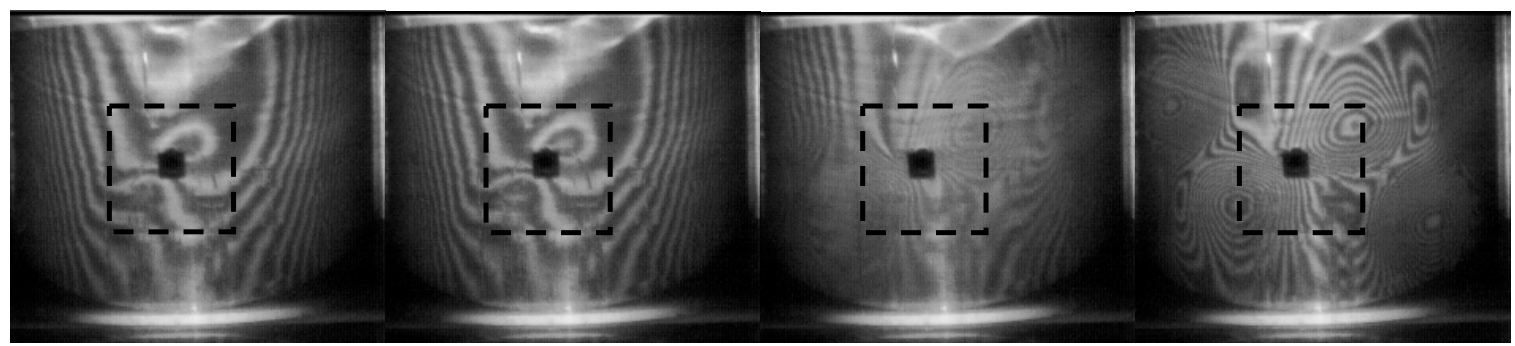
a) initial local buckling
b) local buckling
c) Global buckling
d) Postbuckling
time $=0.0 \mathrm{sec}$
time $=0.001 \mathrm{sec}$
time $=0.002 \mathrm{sec}$
time $=0.004 \mathrm{sec}$

Fig. 17 Observed buckling and postbuckling out-of-plane deformation patterns for specimen C4, quasi-isotropic shell with 1 -in square cutout and 4.4-in square, 1 -ply-thick, $0^{\circ}$ reinforcement.

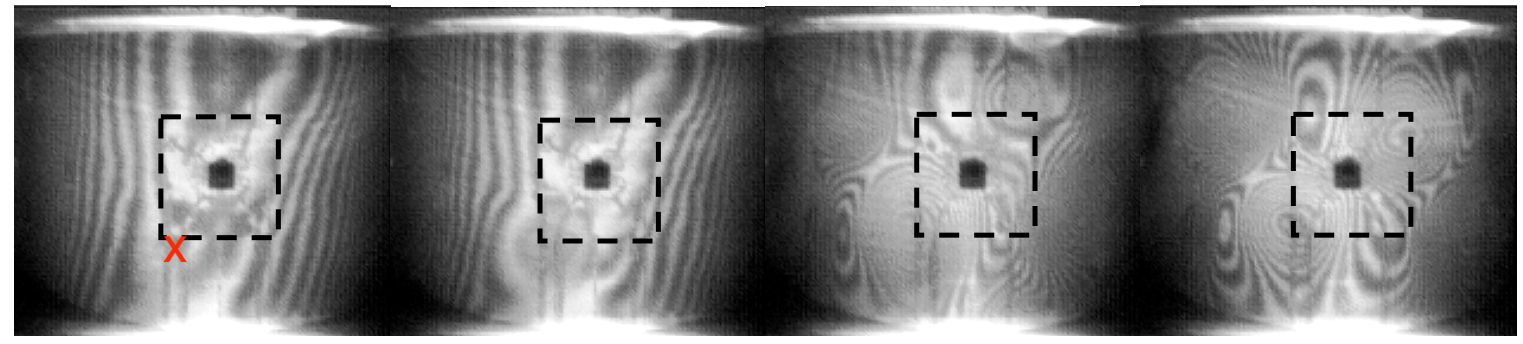
a) initial local buckling
b) local buckling
c) Global buckling
d) Postbuckling
time $=0.0005 \mathrm{sec}$
time $=0.001 \mathrm{sec}$
time $=0.002 \mathrm{sec}$
time $=0.004 \mathrm{sec}$

Fig. 18 Observed buckling and postbuckling out-of-plane deformation patterns for specimen C5, quasi-isotropic shell with 1-in square cutout and 4.4-in square, 2-ply-thick, $0^{\circ}$ reinforcement.

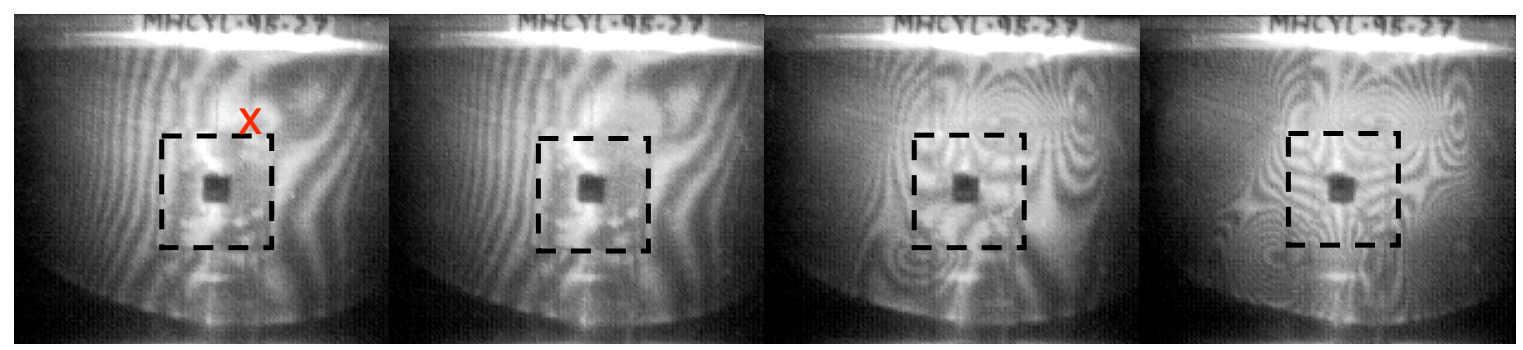
a) initial local buckling
b) local buckling
c) Global buckling
d) Postbuckling time $=0.0005 \mathrm{sec}$ time $=0.001 \mathrm{sec}$ time $=0.002 \mathrm{sec}$ time $=0.004 \mathrm{sec}$

Fig. 19 Observed buckling and postbuckling out-of-plane deformation patterns for specimen C6, quasi-isotropic shell with 1-in square cutout and 4.4-in square, 4-ply-thick, $0^{\circ}$ reinforcement. 


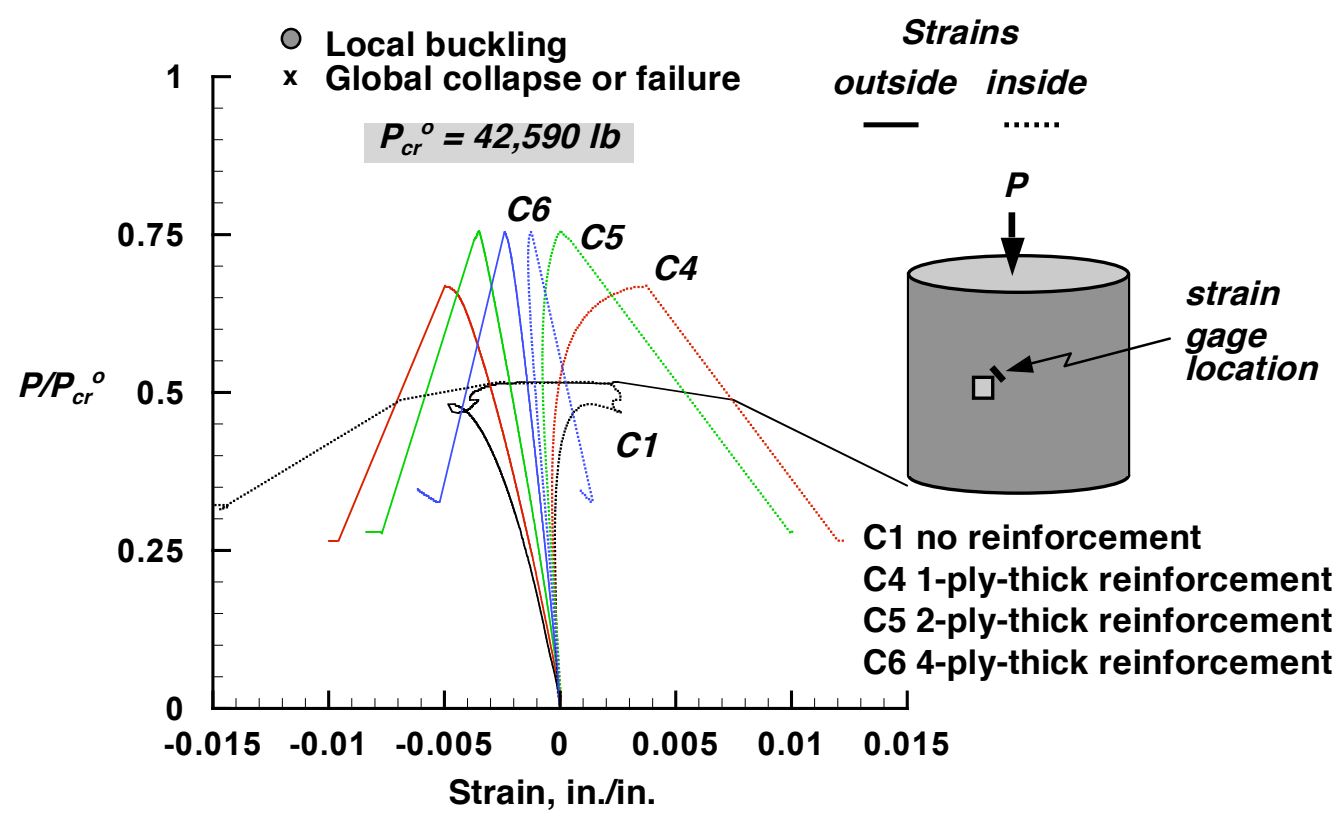

Fig. 20 Load-strain response near 1-in. by 1-1n. square-shaped cutouts compression-loaded quasi-isotropic cylinders $\left(\mathrm{P}_{\mathrm{cr}}{ }^{\mathrm{o}}=42,590 \mathrm{lb}\right.$ is the linear bifurcation buckling load of the corresponding geometrically perfect shell without a cutout).

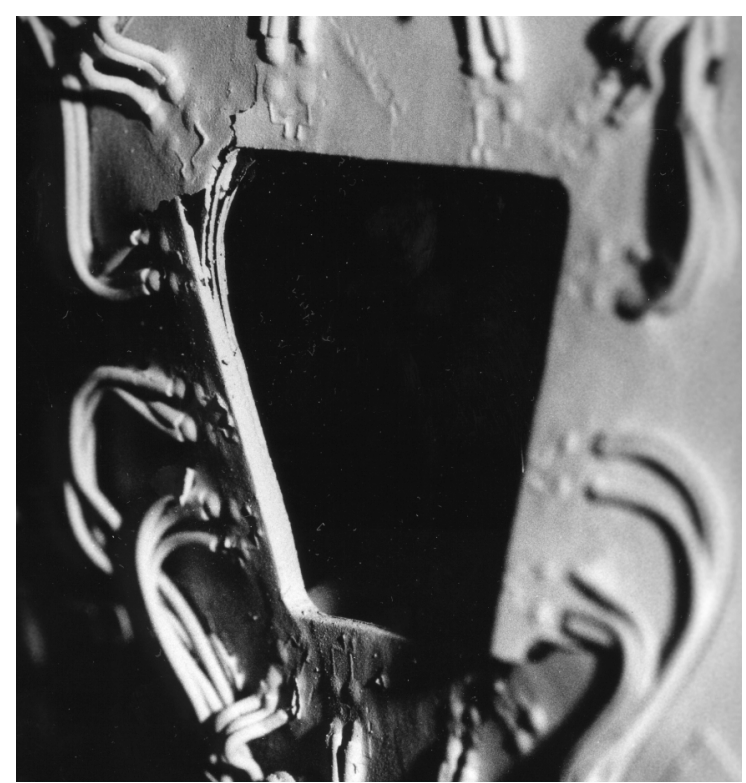

a) Local delamination failures in specimen $\mathrm{C} 5$

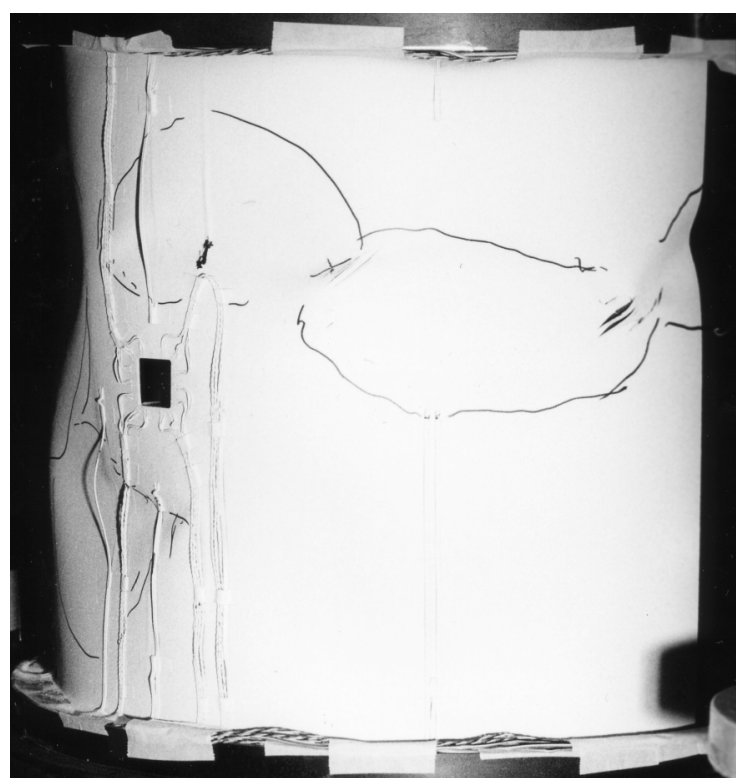

b) Failures in specimen C6

Fig. 21 Observed material failures for specimens C5 and C6. 

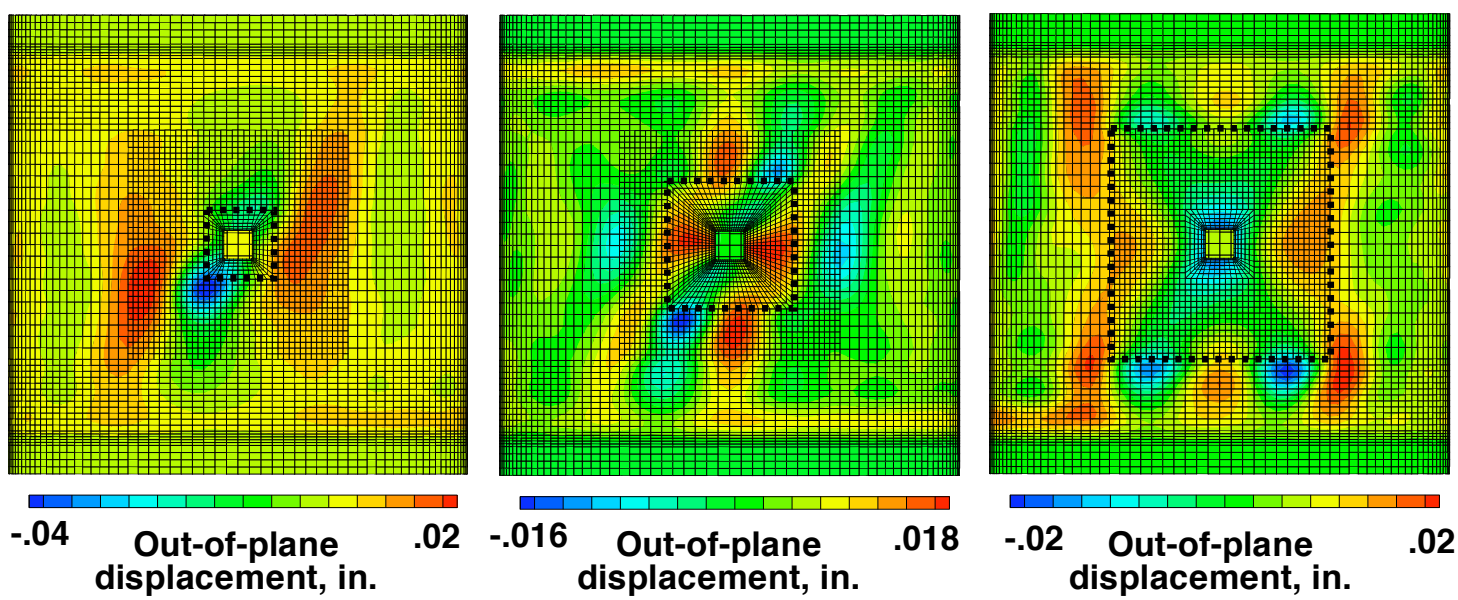

$.02-.016$

Out-of-plane displacement, in.

c) Shell C15

b) Shell C9

Fig. 22 Observed buckling and postbuckling radial deformation patterns for specimen $\mathrm{C} 13, \mathrm{C} 9$, and $\mathrm{C} 15$, quasiisotropic shell with 1-in square cutout and 2.4-in.-sqaure, 4.4-in.-square, and 8.0-in square, 4-ply-thick, $90^{\circ}$ reinforcement, respectively. 